\title{
Molecular diversity and population structure at the Cytochrome P450 3A5 gene in Africa
}

\author{
Ripudaman K Bains ${ }^{1 *}$, Mirna Kovacevic ${ }^{1,2}$, Christopher A Plaster ${ }^{1}$, Ayele Tarekegn ${ }^{3}$, Endashaw Bekele ${ }^{3}$, \\ Neil N Bradman ${ }^{4}$ and Mark G Thomas ${ }^{1,5}$
}

\begin{abstract}
Background: Cytochrome P450 3A5 (CYP3A5) is an enzyme involved in the metabolism of many therapeutic drugs. CYP3A5 expression levels vary between individuals and populations, and this contributes to adverse clinical outcomes. Variable expression is largely attributed to four alleles, CYP3A5*1 (expresser allele); CYP3A5*3 (rs776746), CYP3A5*6 (rs10264272) and CYP3A5*7 (rs41303343) (low/non-expresser alleles). Little is known about CYP3A5 variability in Africa, a region with considerable genetic diversity. Here we used a multi-disciplinary approach to characterize CYP3A5 variation in geographically and ethnically diverse populations from in and around Africa, and infer the evolutionary processes that have shaped patterns of diversity in this gene. We genotyped 2538 individuals from 36 diverse populations in and around Africa for common low/non-expresser CYP3A5 alleles, and re-sequenced the CYP3A5 gene in five Ethiopian ethnic groups. We estimated the ages of low/non-expresser CYP3A5 alleles using a linked microsatellite and assuming a step-wise mutation model of evolution. Finally, we examined a hypothesis that CYP3A5 is important in salt retention adaptation by performing correlations with ecological data relating to aridity for the present day, 10,000 and 50,000 years ago.
\end{abstract}

Results: We estimate that $43 \%$ of individuals within our African dataset express CYP3A5, which is lower than previous independent estimates for the region. We found significant intra-African variability in CYP3A5 expression phenotypes. Within Africa the highest frequencies of high-activity alleles were observed in equatorial and Niger-Congo speaking populations. Ethiopian allele frequencies were intermediate between those of other sub-Saharan African and non-African groups. Re-sequencing of CYP3A5 identified few additional variants likely to affect CYP3A5 expression. We estimate the ages of CYP3A5*3 as $\sim 76,400$ years and CYP3A5*6 as $\sim 218,400$ years. Finally we report that global CYP3A5 expression levels correlated significantly with aridity measures for 10,000 [Spearmann's Rho $=-0.465, p=0.004$ ] and 50,000 years ago [Spearmann's Rho $=-0.379, p=0.02$ ].

Conclusions: Significant intra-African diversity at the CYP3A5 gene is likely to contribute to multiple pharmacogenetic profiles across the continent. Significant correlations between CYP3A5 expression phenotypes and aridity data are consistent with a hypothesis that the enzyme is important in salt-retention adaptation.

Keywords: Cytochrome P450 3A5, Africa, Population genetics, Gene-environment correlations, Pharmacogenetics

\section{Background}

One of the main goals of the genomics revolution has been to characterize diversity within indigenous populations, which have traditionally been under-represented in research. The availability of genomic data is enabling researchers to identify how and why genomic variation affects individual and population differences in clinical

\footnotetext{
* Correspondence: r.bains@ucl.ac.uk

${ }^{1}$ Research Department of Genetics, Evolution and Environment, University College London, Darwin Building, Gower Street, London WC1E 6BT, UK
} Full list of author information is available at the end of the article outcomes following pharmaceutical drug administration. Additionally, evolutionary and demographic processes which have shaped population variation at clinically relevant regions of the human genome are now being determined. Studies of genes encoding drug metabolizing enzymes, such as the Cytochrome P450 (CYP450) superfamily have identified variation which affects the safety and efficacy of therapeutic drugs. However little is known about intra-African variation at these loci. Africa is heavily burdened with common and infectious diseases [1], which are treated with multiple drugs. Studies

\section{Biomed Central}


of intra-African variation at genes encoding drug metabolizing enzymes are likely to be beneficial to clinicians, geneticists and researchers within the emerging field of evolutionary medicine [2]. They are also likely to have great potential for minimizing the risk of adverse clinical outcomes in patients with recent African ancestry [3].

CYP3A enzymes, a sub-family of the CYP450 superfamily, are responsible for the phase I hepatic and intestinal metabolism of a wide spectrum of endogenous and xenobiotic compounds [4]. The two most clinically relevant CYP3A enzymes are CYP3A4 and CYP3A5, which together are involved in the metabolism of $\sim 50 \%$ of all therapeutic drugs [5]. Because of the wide substrate range, some functional variation in CYP3A genes is associated with individual and population differences in pharmacogenetic profiles [6], adverse clinical outcomes [7], and elevated predisposition to diseases $[8,9]$.

There is considerable inter-ethnic variability in CYP3A5 expression levels [10]. Individuals tend to express CYP3A5 at high concentrations (21-202 $\mathrm{pmol} / \mathrm{mg})$ or have significantly reduced, often undetectable, protein levels $(<21 \mathrm{pmol} / \mathrm{mg})$ [11-13]. Variability in protein expression is largely attributed to four CYP3A5 alleles; $C Y P 3 A 5^{*} 1$, an expresser allele, and the low/non-expresser $C Y P 3 A 5 * 3$, $C Y P 3 A 5 \% 6$ and $C Y P 3 A 5 \% 7$ alleles $[13,14]$. Studies have reported that the highest frequencies of high-activity alleles are found in populations with recent African ancestry $[15,16]$. CYP3A5*3 is the main determinant of CYP3A5 expression levels in populations outside Africa [10]. The CYP $3 A 5 * 6$ and $C Y P 3 A 5 * 7$ alleles are observed almost exclusively in individuals with recent African ancestry [13-16], although $C Y P 3 A 5 * 6$ has been observed at low frequency in a sample of individuals from Los Angeles with Mexican ancestry, genotyped as part of the HapMap consortium. CYP $3 A 5 \% 7$ has been observed at a frequency of $3 \%$ in ethnic Koreans [17]. There is some uncertainty over the functionality of the $C Y P 3 A 5 * 6$ mutation. Its effect on protein expression was reported in 2001 [13]. One of two cDNA products isolated from three CYP $3 A 5 \% 1 / C Y P 3 A 5 * 6$ heterozygotes did not contain the sequence for exon 7 . Subsequent western blot analyses of liver samples from two $C Y P 3 A 5 * 1 / C Y P 3 A 5 * 6$ heterozygotes found significantly lower protein levels than in $C Y P 3 A 5^{*} 1$ homozygotes. It has been proposed that $C Y P 3 A 5^{*} 6$ creates an aberrant splicing pathway [13], however this has not been confirmed experimentally. Although data presented by Kuehl et al. suggest that CYP3A5 expression levels in $C Y P 3 A 5 \% 6$ carriers are lower than in CYP3A5\%1 homozygotes, in the absence of expression analysis and more extensive in vivo and in vitro data we considered it prudent to allow for the possibility that in at least some individuals $C Y P 3 A 5 * 6$ is expressed. Unlike the $C Y P 3 A 5 * 3$ and $C Y P 3 A 5 \% 7$ mutations, the association between $C Y P 3 A 5 * 6$ and clinical outcomes is not completely certain. A study examining the association between CYP3A genotypes and the metabolism of midazolam found a significant association between the metabolism of the drug and the presence of the $C Y P 3 A 5 * 3$ allele, but not the $C Y P 3 A 5 * 6$ allele [18]. However, an independent study of Japanese breast cancer patients found that tumor sizes were significantly higher in women who carried the CYP3A5*6 allele [19]. Given this uncertainty we present analyses that assume both that the CYP3A5*6 allele does, and does not affect protein expression and function.

A previous study reported that elevated $C Y P 3 A 5 * 3$ frequencies are positively correlated with increased geographic distance from the equator [20]. There is a latitudinal cline in the frequencies of alleles involved in heat adaptation, and consequently hypertension susceptibility [21]. A strong positive correlation is observed between latitude and functionally important variants of genes implicated in salt-sensitive hypertension, by regulating cardiovascular reactivity and volume avidity, such as angiotensinogen (AGT), G protein $\beta 3$ subunit (GNB3), and epithelial sodium channel $\gamma(E N a C \gamma)$ [21]. CYP3A5 is involved in the metabolism of renal cortisol to $6-\beta$ -hydroxycortisol, a key regulator of renal sodium transport, and immune responses which cause inflammation [22]. It has been proposed that the expresser $C Y P 3 A 5 * 1$ allele provides a selective advantage in equatorial populations due to the role of CYP3A5 in salt retention and the reabsorption of water $[13,20]$. Conversely, elevated CYP $3 A 5 * 1$ frequencies are hypothesized to be detrimental and are associated with elevated risk of salt-sensitive hypertension in non-equatorial populations [8,23,24]. The CYP3A5 gene region has high frequencies of derived, functional alleles [25], and substantial population differentiation in the frequencies of the CYP $3 A 5 * 3$ allele when compared to neutral markers, as measured by weighted $F_{\mathrm{ST}}$ tests, [26]. This suggests that low/non-expression of CYP3A5 may be adaptive in non-equatorial populations.

Although CYP3A5 expression in Africa is likely to be highly variable, few previous studies have characterized intra-African diversity in CYP $3 A 5$ and other clinically relevant genes. High levels of genetic diversity are observed within the continent compared to other geographic regions, and this is consistent with a recent African origin model of human evolution [27]. East Africa is a particularly diverse region of the continent. Reports have shown a gradual reduction in genetic diversity with increased geographic distance from Ethiopia [28-30] indicating that the region is one of the most genetically diverse in the world. Studies of functional variation in clinically relevant genes have found significant inter-ethnic differences within Ethiopia and between Ethiopian and other African populations [31-33]. These data highlight the potential that focused genetic studies of clinically relevant variation within 
Ethiopian populations have for understanding intraAfrican genetic diversity.

Within this study we have focused on characterizing CYP3A5 variation in multiple geographically and ethnically diverse populations sampled from in and around Africa. We focused on determining population structure at this locus, and identified considerable population structuring within Africa. These results suggest that there are likely to be multiple pharmacogenetic profiles across Africa which could affect the safety and efficacy of many therapeutic drugs which are CYP3A5 substrates. Additionally, we report correlations between CYP3A5 expression phenotypes and aridity data for 10,000 and 50,000 years ago, consistent with a previous hypothesis that the enzyme is involved in salt retention/heat adaptation. This suggests that global variability in expression phenotypes may have occurred as a result of selective pressures on the gene.

\section{Results}

The prevalence of clinically relevant CYP3A5 alleles in Africa

We genotyped 2245 individuals from 32 geographically and ethnically diverse African populations for common clinically relevant CYP3A5 alleles. An additional 293 individuals from four non African populations from Europe and the Arabian Peninsula were also genotyped to permit comparisons of African diversity in a global context (Table 1). Prior to our study, the distribution of clinically relevant $C Y P 3 A 5$ alleles across Africa, and relative to non-African populations, was unknown. We identified CYP $3 A 5 \% 1, C Y P 3 A 5 * 3$ and $C Y P 3 A 5 \% 6$ in all genotyped African population samples (allele frequency ranges: 4-81\%, 4-81\% and 4-33\% respectively). CYP3A5*7 was confined almost exclusively to Niger-Congo speaking samples (range: 0-22\%). The distribution of CYP3A5 alleles is structured by major language family and geographic region, as evidenced by Analysis of Molecular Variance $[P<0.0001$ for both variables]. Pearson's $X^{2}$ tests were carried out to examine within-region differences. Considerable heterogeneity was observed in East Africa $\left[\chi^{2}=157.69\right.$, d.f. $\left.=21, p<0.0001\right]$ and North Africa $\left[\chi^{2}=37.61\right.$, d.f. $\left.=9, p<0.01\right]$ but not in any other geographic region. The genotyped loci are in complete LD $\left(D^{\prime}=1, \quad p<0.0001\right)$, except between the $C Y P 3 A 5 * 6$ and $C Y P 3 A 5^{*} 1 / * 3$ loci $\left(D^{\prime}=0.96, p<0.0001\right)$. A low frequency recombinant haplotype was observed in 10 heterozygotes explaining why $D^{\prime}$ between $C Y P 3 A 5 * 1$ and $C Y P 3 A 5^{*} 6$ is not equal to 1 . Haplotype analysis found that the low/non-expresser CYP3A5 alleles occur predominantly on independent haplotype backgrounds (Figure 1 and Additional file 1 Table S1) suggesting that their convergent effects on CYP3A5 expression are independent. A significant correlation between pairwise genetic $\left(F_{\mathrm{ST}}\right)$ and geographic distances (kilometers) was observed using a Mantel test when all populations genotyped in this study $(n=36)$ were analyzed [Mantel $r$ statistic $=0.228, p<0.0001$ ].

The geographic and ethnic distributions of low-, intermediate- and high-expression phenotypes, based on haplotype frequencies were inferred. Expresser phenotypes were inferred assuming that $C Y P 3 A 5 \% 6$ does and does not cause a low/non-expression phenotype (Additional file 2 Figure S1 and Additional file 3 Figure S2 respectively). The distributions in both Figures show that the highest frequencies of high-activity phenotypes are in equatorial regions of Africa, and Ethiopia has the highest within country inter-ethnic diversity, which is driven by differences between the Anuak and other Ethiopian groups.

\section{Correlations between ecological variables and inferred CYP3A5 expression phenotypes}

A previous study reported a strong positive correlation between $C Y P 3 A 5 * 3$ allele frequencies and latitude [20]. Latitude is a correlate of multiple ecological variables that are associated with functional markers of genes involved in heat adaptation [21]. We tested for correlations between frequencies of low/non-expresser CYP3A5 alleles, and inferred expresser phenotypes, with latitude and the ecological variables; temperature and precipitation (Table 2). Additionally, we tested for correlations with aridity indices calculated from temperature and precipitation data using the de Martonne aridity index [34]. This enabled us to consider the combined effect of temperature and precipitation on CYP3A5 phenotypes. Correlations were estimated using ecological data for the present day, and inferred for 10, 000 years ago (Holocene) and 50,000 years ago (Late Pleistocene) (http://badc.nerc.ac.uk/home/index.html). Correlations were performed assuming that $C Y P 3 A 5^{*} 6$ is a low/ non-expresser allele, and that it is a neutral allele.

Latitude correlated significantly with CYP3A5 expression in Africa [Spearmann's Rho $=-0.472, p=0.004$ ], the correlation remained significant when considering north [Spearmann's Rho $=-0.659, p<0.0001$ ] and south latitude [Spearmann's Rho $=-0.701, p<0.0001]$ populations separately. Across a global cohort (87 populations) which, included published genotyping data [20] and where $C Y P 3 A 5 * 3$ alone is considered to predict CYP3A5 expression levels, a significant correlation between latitude and frequencies of this allele was seen only for north latitude populations [Spearmann's Rho $=0.666, p<0.0001$ ], but not south [Spearmann's Rho $=0.066, p=0.759$ ]. No significant correlation was observed between aridity values for the present day and expresser phenotypes when $C Y P 3 A 5 * 6$ was considered a low/non expresser allele [Spearmann's Rho $=-0.185, p=0.279$ ] or a neutral allele [Spearmann's Rho $=-0.0288, p=0.868$ ]. Expresser phenotypes correlated significantly with aridity values from the Holocene [Spearmann's Rho $=-0.465, p=0.004$ ] and Late Pleistocene [Spearmann's Rho $=-0.379, p=0.02$ ] when $C Y P 3 A 5 * 6$ 
was considered as a low/non-expresser mutation. We subsequently examined independent correlations between expresser allele frequencies and temperature and precipitation. We found significant correlations between expresser allele frequencies and temperature for every time period, both when $C Y P 3 A 5 \% 6$ was considered to be a low/ non-expresser mutation and a neutral allele $(p<0.0001$ for every correlation, see Table 2). No significant correlation was observed between precipitation values and expresser allele frequencies.

We subsequently examined the correlations between present day ecological data and expresser allele frequencies, while controlling for geographic distances between populations, using partial Mantel tests. For each correlation $C Y P 3 A 5 \% 6$ was assumed to be a low/non-expresser mutation. We found that the correlation between CYP3A5 expresser alleles and temperature remained significant when controlling for geographic proximity between populations [Mantel $r$ statistic $=0.398, p=0.02$ ]. However the correlation with latitude was no longer significant [Mantel $r$ statistic $=0.202, p=0.05]$.

\section{CYP3A5 variation observed in Ethiopia}

Previous studies of genetic variation in drug metabolizing enzymes have identified considerable inter-ethnic diversity within Ethiopia and between Ethiopian and other African populations [31-33]. The results from our geographic survey of clinically relevant $C Y P 3 A 5$ variants also indicated that there is considerable heterogeneity within Ethiopia, and between Ethiopia and other African populations. We performed a re-sequencing survey of the CYP3A5 gene in five Ethiopian populations to characterize $C Y P 3 A 5$ diversity in greater detail.

We observed significant inter-ethnic diversity in CYP3A5 allele frequencies in Ethiopia. To identify additional variation and elucidate intra-Ethiopian population structure we re-sequenced an $8063 \mathrm{bp}$ region of $C Y P 3 A 5$, which included the CYP3A5 promoter, exons and exonflanking introns, in five Ethiopian populations. 51 polymorphic sites were identified (Table 3). Nine (17.6\%) were exonic and, 3 out of 5 (6\%) identified non-synonymous polymorphisms were predicted to adversely alter protein function. No significant difference in the proportion of synonymous or non-synonymous variation was identified by a codon-based Z-test [35] $(Z=0.961$ and $p=0.169)$. The proportion of amino acid changes that we observed at the CYP3A5 gene (5 changes $/ 502$ codons $=\sim 1 \%$ ) is higher than previously reported for 103 protein-coding genes (147 changes/26,999 codons=0.56\%) [36], although the differences are not significant [paired $t$ test, $t=1.01$, d.f. $=1$, $p=0.50]$. We did not identify any variants in experimentally established transcription factor binding sites $[37,38]$. Eight of the nine identified promoter variants occurred in nucleotide positions that are highly conserved in primates (i.e. where the allele is the same in all primate species), and bioinformatic analyses predicted that four out of nine may affect transcription factor binding. Of all identified polymorphisms - predicted and previously reported to affect CYP3A5 expression and activity $(n=10)-4$ (2 promoter, $C Y P 3 A 5 * 3$ and $C Y P 3 A 5 * 6$ ) occurred at frequencies over $1 \%$. The highest frequency variants identified were $C Y P 3 A 5 * 3, C Y P 3 A 5 * 6$ and the non-functional variant rs15524, which is found in high LD with CYP3A5*3 [39].

\section{Ethiopian CYP3A5 variation in the context of other geographic populations}

We analyzed the Ethiopian re-sequencing data along with those previously reported for three ethnically diverse populations from the Corriell Repositories to analyze the data in a global context [20] (Table 4). The results of the HudsonKreitman-Aguadé (HKA) test [40], comparing intra- and inter-species CYP3A5 diversity, was not significant $(p=0.6346)$. Tajima's $D$, Li's $D^{*}$ and $F^{*}, \mathrm{Fu}$ and Li's $F$ and $D$ (using chimpanzee sequence to establish ancestral states), and Fu's $F_{S}$ all indicated a skew towards rare variants in every population, which is consistent with general human population growth or positive selection. Fu and Li's $D^{*}$ and $F^{*}$ reported a significant departure from neutrality for both Europeans and the Anuak, although significance was only reached for Europeans following Bonferonni correction (8 tests). Fu and Li's $F_{S}$ reported a significant departure from neutrality for 7 of the 8 populations after Bonferonni correction. Strobeck's $S$ results were consistent with Fu's $F_{S}$ as expected. The results of the $H$ test, used to assess whether there is an excess of high frequency derived variants [41], were not significant in any population $(p>0.05)$, however nucleotide diversity at CYP3A5 is low and this may be affecting the tests.

72 haplotypes were inferred from allelic data for all 8 Ethiopian population samples, 33 (45.8\%) containing CYP3A5*1, 29 (40.3\%) containing CYP3A5*3, 7 (9.7\%) containing $C Y P 3 A 5 * 6,1$ (1.4\%) containing $C Y P 3 A 5 * 7$, and $2(2.8 \%)$ containing both $C Y P 3 A 5 \% 3$ and $C Y P 3 A 5 \% 6$ (Additional file 4 Figures $\mathrm{S} 3 \mathrm{a}$ and $\mathrm{b}$ ). LD across the gene is high. A phylogeny, based on network analysis of the haplotype data, is presented in Figure 2. 98\% of European and $83 \%$ of Han Chinese haplotypes contain the CYP $3 A 5 * 3$ allele, as do $64 \%$ of Afar haplotypes and $\sim 67 \%$ in both the Amhara and Oromo. Gene diversity is highest in African Americans $(0.963 \pm 0.02)$ and lowest in Europeans $(0.589 \pm 0.08)$. The $C Y P 3 A 5 * 1$ haplogroup is significantly more diverse than the other haplogroups $(0.921 \pm 0.01)(p<0.0001$ for every comparison). Population differentiation was measured by pairwise $F_{\mathrm{ST}}$ (Table 5). The Afar, Amhara and Oromo are intermediate between individuals with recent African ancestry and Han Chinese and European groups. We placed population structure seen at the CYP3A5 gene in a wider genomic 
Table 1 Genotype and allele frequencies and tests for deviation from Hardy-Weinberg Equilibrium ( $x^{2} p$-values given)

\begin{tabular}{|c|c|c|c|c|c|c|c|c|c|c|c|c|c|c|c|c|c|c|c|c|}
\hline \multirow[t]{2}{*}{ Region } & \multirow[t]{2}{*}{ Country } & \multirow[t]{2}{*}{ Population } & \multicolumn{6}{|c|}{ CYP3A5*1/CYP3A5*3 } & \multicolumn{6}{|c|}{ CYP $3 A 5 * 6$} & \multicolumn{6}{|c|}{ CYP $3 A 5 * 7$} \\
\hline & & & AA & AG & GG & Total & G [*3] & HWE & GG & GA & AA & Total & $A[* 6]$ & HWE & $-1-$ & $-/ T$ & $\mathrm{~T} / \mathrm{T}$ & Total & $\mathrm{T}[* 7]$ & HWE \\
\hline \multirow[t]{2}{*}{ Europe } & Armenia & Southern Armenians & 0 & 10 & 90 & 100 & 0.95 & 1.00 & 100 & 0 & 0 & 100 & 0.00 & $\mathrm{~N} / \mathrm{A}$ & 100 & 0 & 0 & 100 & 0.00 & N/A \\
\hline & Turkey & Anatolian Turks & 2 & 10 & 62 & 74 & 0.91 & 0.11 & 74 & 0 & 0 & 74 & 0.00 & N/A & 74 & 0 & 0 & 74 & 0.00 & N/A \\
\hline Arabian & Yemen & Yemeni from Hadramaut & 2 & 21 & 59 & 82 & 0.85 & 1.00 & 77 & 5 & 0 & 82 & 0.03 & 1.00 & 80 & 2 & 0 & 82 & 0.01 & 1.00 \\
\hline Peninsula & & Yemeni from Sena and Msila & 7 & 17 & 13 & 37 & 0.58 & 0.74 & 29 & 7 & 1 & 37 & 0.12 & 0.42 & 35 & 2 & 0 & 37 & 0.03 & 1.00 \\
\hline \multirow[t]{4}{*}{ North Africa } & Algeria & Northern Algerians & 9 & 42 & 108 & 159 & 0.81 & 0.12 & 146 & 15 & 0 & 161 & 0.05 & 1.00 & 159 & 2 & 0 & 161 & 0.01 & 1.00 \\
\hline & Morocco & Berbers & 3 & 28 & 54 & 85 & 0.80 & 1.00 & 79 & 7 & 0 & 86 & 0.04 & 1.00 & 85 & 1 & 0 & 86 & 0.01 & 1.00 \\
\hline & Sudan & Northern Sudanese & 24 & 58 & 51 & 133 & 0.60 & 0.29 & 104 & 28 & 0 & 132 & 0.11 & 0.36 & 135 & 1 & 0 & 136 & 0.00 & 1.00 \\
\hline & & Sudanese from Kordofan & 11 & 11 & 8 & 30 & 0.45 & 0.16 & 19 & 10 & 1 & 30 & 0.20 & 1.00 & 29 & 1 & 0 & 30 & 0.02 & N/A \\
\hline \multirow[t]{8}{*}{ East Africa } & Ethiopia & Afar & 10 & 31 & 32 & 73 & 0.65 & 0.61 & 47 & 26 & 0 & 73 & 0.18 & 0.11 & 73 & 0 & 0 & 73 & 0.00 & N/A \\
\hline & & Amhara & 14 & 22 & 40 & 76 & 0.67 & 0.004 & 55 & 19 & 2 & 76 & 0.15 & 0.67 & 76 & 0 & 0 & 76 & 0.00 & N/A \\
\hline & & Anuak & 38 & 32 & 6 & 76 & 0.29 & 1.00 & 44 & 25 & 7 & 76 & 0.26 & 0.23 & 75 & 1 & 0 & 76 & 0.01 & 1.00 \\
\hline & & Maale & 20 & 36 & 19 & 75 & 0.49 & 0.82 & 53 & 22 & 0 & 75 & 0.15 & 0.34 & 74 & 1 & 0 & 75 & 0.01 & 1.00 \\
\hline & & Oromo & 12 & 28 & 34 & 74 & 0.65 & 0.20 & 55 & 19 & 1 & 75 & 0.14 & 1.00 & 75 & 0 & 0 & 75 & 0.00 & N/A \\
\hline & Republic of South Sudan & Southern Sudanese & 74 & 42 & 9 & 125 & 0.24 & 0.46 & 58 & 50 & 15 & 123 & 0.33 & 0.42 & 117 & 8 & 0 & 125 & 0.03 & 1.00 \\
\hline & Tanzania & Chagga & 28 & 18 & 4 & 50 & 0.26 & 0.71 & 36 & 14 & 0 & 50 & 0.14 & 0.57 & 41 & 9 & 0 & 50 & 0.09 & 1.00 \\
\hline & Uganda & Bantu speakers from Ssese & 36 & 3 & 0 & 39 & 0.04 & 1.00 & 22 & 17 & 0 & 39 & 0.22 & 0.16 & 23 & 16 & 0 & 39 & 0.21 & 0.31 \\
\hline \multirow[t]{5}{*}{ West Africa } & Ghana & Asante & 27 & 8 & 0 & 35 & 0.11 & 1.00 & 20 & 13 & 1 & 34 & 0.22 & 1.00 & 29 & 5 & 0 & 34 & 0.07 & 1.00 \\
\hline & & Bulsa & 58 & 29 & 3 & 90 & 0.19 & 1.00 & 61 & 28 & 0 & 89 & 0.16 & 0.11 & 69 & 19 & 2 & 90 & 0.13 & 0.62 \\
\hline & & Kasena & 28 & 17 & 2 & 47 & 0.22 & 1.00 & 31 & 16 & 0 & 47 & 0.17 & 0.32 & 35 & 12 & 0 & 47 & 0.13 & 1.00 \\
\hline & Senegal & Manjak & 57 & 29 & 4 & 90 & 0.21 & 1.00 & 59 & 24 & 9 & 92 & 0.23 & 0.02 & 81 & 13 & 0 & 94 & 0.07 & 1.00 \\
\hline & & Wolof & 55 & 31 & 8 & 94 & 0.25 & 0.27 & 58 & 31 & 1 & 90 & 0.18 & 0.29 & 78 & 15 & 1 & 94 & 0.09 & 0.55 \\
\hline West Central & Cameroon & Kotoko & 18 & 21 & 0 & 39 & 0.27 & 0.04 & 23 & 16 & 1 & 40 & 0.23 & 0.65 & 36 & 4 & 0 & 40 & 0.05 & 1.00 \\
\hline \multirow[t]{5}{*}{ Africa } & & Shewa Arabs & 26 & 31 & 12 & 69 & 0.40 & 0.62 & 42 & 24 & 3 & 69 & 0.22 & 1.00 & 60 & 9 & 0 & 69 & 0.07 & 1.00 \\
\hline & & Mayo Darle & 66 & 38 & 13 & 117 & 0.27 & 0.06 & 71 & 33 & 13 & 117 & 0.25 & 0.01 & 102 & 15 & 0 & 117 & 0.06 & 1.00 \\
\hline & & Somie, Cameroonian Grassfields & 36 & 28 & 1 & 65 & 0.23 & 0.16 & 44 & 19 & 2 & 65 & 0.18 & 1.00 & 52 & 13 & 0 & 65 & 0.10 & 1.00 \\
\hline & Congo & Congolese from Brazzaville & 35 & 18 & 2 & 55 & 0.20 & 1.00 & 43 & 11 & 1 & 55 & 0.12 & 0.55 & 45 & 10 & 0 & 55 & 0.09 & 1.00 \\
\hline & Nigeria & Igbo & 64 & 23 & 0 & 87 & 0.13 & 0.35 & 60 & 24 & 4 & 88 & 0.18 & 0.47 & 73 & 12 & 2 & 87 & 0.09 & 0.14 \\
\hline
\end{tabular}


Table 1 Genotype and allele frequencies and tests for deviation from Hardy-Weinberg Equilibrium ( $x^{2} p$-values given) (Continued)

\begin{tabular}{|c|c|c|c|c|c|c|c|c|c|c|c|c|c|c|c|c|c|c|c|c|}
\hline$\overline{\text { South East }}$ & Malawi & Chewa & 66 & 25 & 1 & 92 & 0.15 & 1.00 & 66 & 23 & 3 & 92 & 0.16 & 0.69 & 60 & 31 & 0 & 91 & 0.17 & 0.06 \\
\hline \multirow[t]{8}{*}{ Africa } & & Lomwe & 13 & 4 & 1 & 18 & 0.17 & N/A & 10 & 8 & 0 & 18 & 0.22 & N/A & 14 & 4 & 0 & 18 & 0.11 & N/A \\
\hline & & Ngoni & 15 & 2 & 1 & 18 & 0.11 & N/A & 9 & 6 & 3 & 18 & 0.33 & N/A & 16 & 2 & 0 & 18 & 0.06 & $\mathrm{~N} / \mathrm{A}$ \\
\hline & & Tumbuka & 44 & 18 & 0 & 62 & 0.15 & 0.34 & 40 & 17 & 5 & 62 & 0.22 & 0.14 & 45 & 17 & 0 & 62 & 0.14 & 0.59 \\
\hline & & Yao & 37 & 18 & 1 & 56 & 0.18 & 0.67 & 43 & 12 & 1 & 56 & 0.13 & 1.00 & 46 & 10 & 0 & 56 & 0.09 & 1.00 \\
\hline & Mozambique & Sena & 58 & 21 & 3 & 82 & 0.16 & 0.44 & 51 & 28 & 5 & 84 & 0.23 & 0.75 & 59 & 25 & 1 & 85 & 0.16 & 0.68 \\
\hline & South Africa & Bantu speakers & 22 & 17 & 2 & 41 & 0.26 & 1.00 & 29 & 9 & 3 & 41 & 0.18 & 0.10 & 34 & 4 & 2 & 40 & 0.10 & 0.03 \\
\hline & Zimbabwe & Lemba & 17 & 6 & 0 & 23 & 0.13 & 1.00 & 13 & 10 & 1 & 24 & 0.25 & 1.00 & 17 & 7 & 0 & 24 & 0.15 & 1.00 \\
\hline & & Zimbabweans from Mposi & 36 & 7 & 4 & 47 & 0.16 & 0.008 & 36 & 10 & 3 & 49 & 0.16 & 0.09 & 34 & 16 & 2 & 52 & 0.19 & 1.0 \\
\hline
\end{tabular}

HWE could not be calculated for the Lomwe and Ngoni as both populations had fewer than 50 chromosomes meaning that the test had insufficient power. No population deviated from Hardy-Weinberg equilibrium, following Bonferonni correction (for CYP3A5*3: adjusted $p$ value $=0.00139$; correction for 36 tests, for $C Y P 3 A 5^{*} 6$ : adjusted $p$ value $=0.0015$; correction for 34 tests, for $C Y P 3 A 5^{*} 7$ : adjusted $p$ value $=0.0017$; correction for 30 tests). Deviations from HWE cannot be calculated for monomorphic loci: labeled "N/A" on the Table. "Total" refers to the number of individuals, from a given population, successfully genotyped at each locus. Population refers to the grouping of individuals either by self-declared ethnicity or geography/place collected. 
context by analyzing intra-Ethiopian differentiation at markers on the non-recombining regions of the Y chromosome (NRY) and the mitochondrial genome (hypervariable region 1 [HVS1] and coding region SNPs) [42]. We compared Ethiopian NRY and HVS1 genotypes with data for 92 Fars from Iran, 95 Nigerian Igbo, 126 Greek-Cypriots and 60 Halfawi from the Republic of Sudan. The Anuak are outliers compared to the other Ethiopian populations (data not shown), consistent with genome wide-markers [43] and what we report for CYP3A5. Intra-Ethiopian population structure at the $C Y P 3 A 5$ gene is also consistent with that seen at other drug metabolizing genes $C Y P 1 A 2$ [31], and UGT1A1 [32].

\section{Estimating the age of clinically relevant CYP3A5 alleles}

The age of an allele is the time since it arose by mutation $[44,45]$. Estimating the ages of CYP3A5 alleles may help to identify specific demographic processes which have affected inter-population differences in allele frequencies, or identify an important role for natural selection in selecting for specific alleles [44]. Under the stepwise mutation model of microsatellite evolution, and assuming no recombination, we estimated the time to the most recent ancestor (TMRCA) of the CYP3A5*3 mutation to be 2388 generations (95\% confidence intervals [C.I.]: 1797-3211) and $C Y P 3 A 5 \% 6$ to be 6825 generations (95\% C.I.: 3086$11,975)$. Assuming that a generation is 32 years [46], the estimated age of the $C Y P 3 A 5 * 3$ mutation is $\sim 76,416$ years (95\% C.I. 57,504-102,752 years) and CYP3A5*6 is 218,400 years (95\% C.I. 98,752-383,200 years) (Table 6). Our estimates of the age of $C Y P 3 A 5 * 3$ is consistent with its presence within and outside of Africa. The distribution of the CYP3A5\%6 allele shows some similarity to that of FMO2*1, an allele of the gene encoding the drug metabolizing enzyme FMO2 [33]. FM02*1 occurs at similar frequencies across Africa and is not found at high frequencies outside of the continent. The estimated age of FMO2 1 is 502,404 years (95\% C.I. 154,790-1,041,243 years) based on a coalescent simulation [47] and using data from populations re-sequenced as part of the NIEHS SNPs database (http:// egp.gs.washington.edu/). The age estimates of both the CYP3A5*6 and $F M O 2 * 1$ alleles predate estimates of the range-expansion of modern humans out of Africa.

\section{Discussion}

We performed an extensive geographic survey of clinically relevant $C Y P 3 A 5$ alleles in a large African cohort and found highly variable frequencies of the ancestral $C Y P 3 A 5 * 1$ allele (9-96\%) across the continent. We estimate that $\sim 43 \%$ of individuals within our African dataset express CYP3A5, which is much lower than all other previous estimates for the continent (between 55-95\%) $[15,16]$. The classification of CYP3A5 alleles as expresser or low/non-expresser will affect estimates of expresser frequencies in Africa. In vitro studies of CYP3A5 expression levels in $C Y P 3 A 5 * 6$ homozygotes are needed to establish the effect of the mutation on protein expression. The results from such studies may alter the classification of $C Y P 3 A 5 \% 6$ as a clinically relevant $C Y P 3 A 5$ allele, and mean that CYP3A5 protein expression levels across Africa are likely to be consistent with those presented in Additional file 3 Figure S2 . Our estimates of the proportion of CYP3A5 expressers differ across Africa, consistent with the Sahara acting as a barrier to gene flow $[48,49]$. Additionally, we estimate that the proportion of CYP3A5 expressers in East Africa $(\sim 36 \%)$ is lower than in other regions of sub-Saharan Africa ( 45\%), and report considerable heterogeneity among Ethiopian ethnic groups (17-54\%). We found that the highest frequencies of inferred high-activity phenotypes were seen in equatorial and Niger-Congo speaking populations.

From the geographic survey we observed that the Ethiopian allele frequencies are intermediate between subSaharan African and Eurasian groups [50]. Our study has extended previous work on CYP3A5 in Ethiopia [51] by accounting for, and identifying, considerable inter-ethnic variability within the country. CYP3A5 haplotype diversity and structure in the Afar, Amhara and Oromo were characteristic of that seen in European Caucasians and Han Chinese individuals. There is a known Arabian contribution to Ethiopian ancestry as a result of migration of Semitic groups into the region, which has influenced genetic diversity $[48,52]$. We further examined intra-Ethiopian diversity at mitochondrial and Y-chromosome genetic markers and found that the Anuak were outliers. This suggests that the intra-Ethiopian diversity we observed can be explained by Arabian admixture in the Afar, Amhara and Oromo, rather than differential selection pressures on CYP3A5.

Considerable intra-African population structuring at the CYP3A5 gene suggests that there are likely to be multiple pharmacogenetics profiles for key drugs used across the continent, including many used in the treatment and control of malaria [53] and HIV-1 [54]. We identified significant differences between Ethiopians and other sub-Saharan African populations, and intra-Ethiopian diversity, at the CYP3A5 gene. The results from our study suggest that East Africans are likely to be distinct from a wider cohort of African patients, and that there are likely to be inter-ethnic differences within East Africa. The results from large surveys [32,33], including our study, emphasize the importance of including sub-Saharan African populations in pharmacogenetics research; over $90 \%$ of the global disease burden is found in developing countries [55,56]. An appreciable number of the diseases found within the region are treated with CYP3A5 substrates [5,57] at doses optimized for patients with recent European ancestry [26]. Larger and 


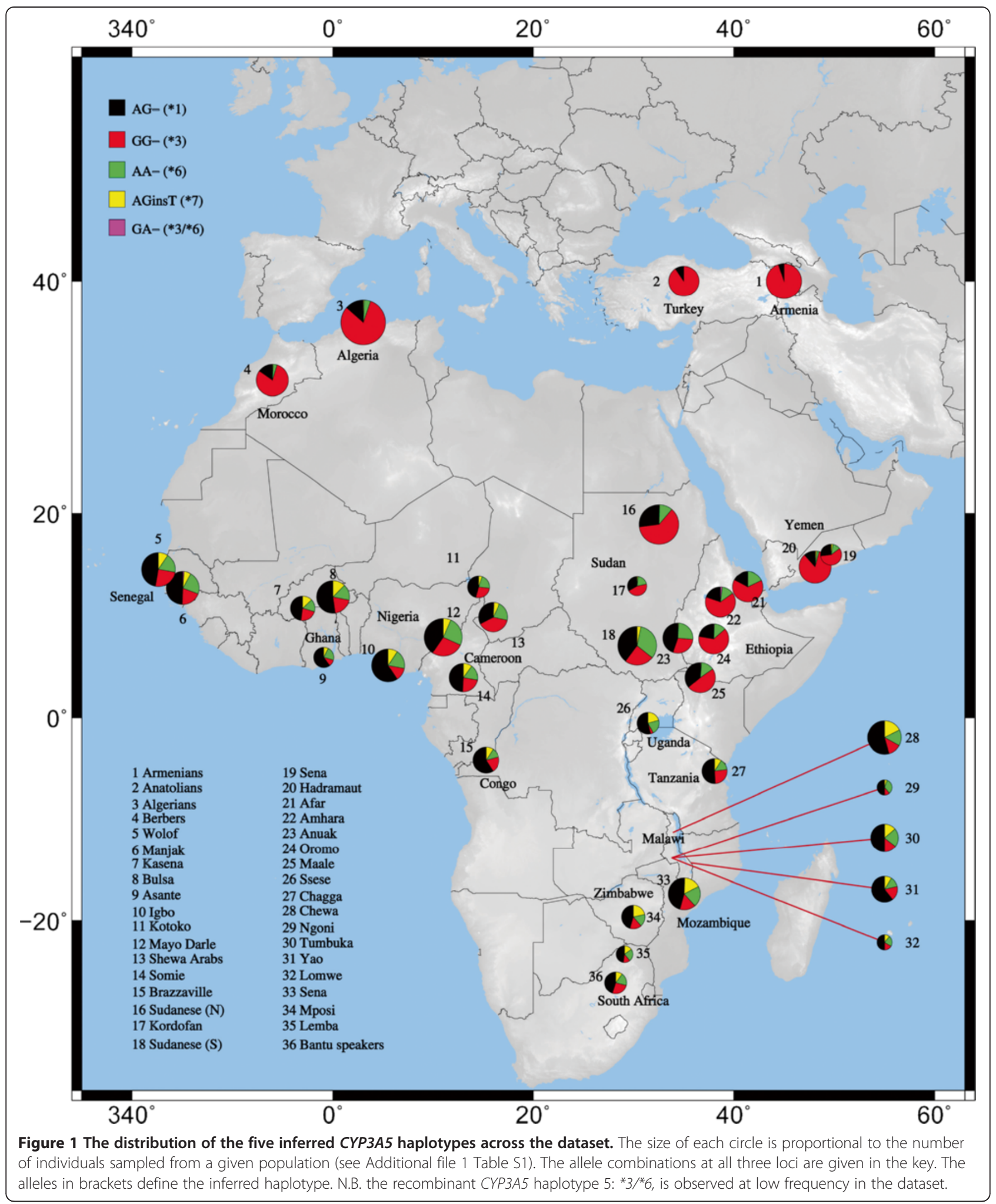


Table 2 Correlation analyses, between ecological variables and CYP3A5 allelic and inferred expression data

\begin{tabular}{|c|c|c|c|c|c|c|c|c|c|c|c|c|c|c|c|}
\hline \multirow[t]{3}{*}{ Time period } & \multirow[t]{3}{*}{ Ecological variable } & \multirow{2}{*}{\multicolumn{2}{|c|}{$\begin{array}{l}N=87 \\
C Y P 3 A 5 * 3\end{array}$}} & \multicolumn{12}{|l|}{$N=36$} \\
\hline & & & & \multicolumn{2}{|c|}{ CYP3A5*6 } & \multicolumn{2}{|c|}{ CYP3A5*7 } & \multicolumn{2}{|c|}{$\begin{array}{l}\text { High expresser allele } \\
\text { (assuming CYP3A5*6 } \\
\text { is a low/non- } \\
\text { expresser allele) }\end{array}$} & \multicolumn{2}{|c|}{$\begin{array}{l}\text { Low expresser allele } \\
\text { (assuming CYP } 3 A 5^{*} 6 \\
\text { is a low/non-expresser } \\
\text { allele) }\end{array}$} & \multicolumn{2}{|c|}{$\begin{array}{l}\text { High expresser allele } \\
\text { (assuming CYP } 3 A 5^{*} 6 \text { is } \\
\text { not a low/non- } \\
\text { expresser allele) }\end{array}$} & \multicolumn{2}{|c|}{$\begin{array}{l}\text { Low expresser allele } \\
\text { (assuming CYP3A5*6 } \\
\text { is not a low/non- } \\
\text { expresser allele) }\end{array}$} \\
\hline & & Rho & $P$-value & Rho & $P$-value & Rho & $P$-value & Rho & $P$-value & Rho & $P$-value & Rho & $P$-value & Rho & $P$-value \\
\hline & Latitude & 0.706 & $<0.0001$ & -0.331 & 0.048 & -0.177 & 0.303 & -0.472 & 0.004 & 0.472 & 0.004 & -0.416 & 0.012 & 0.416 & 0.012 \\
\hline & North latitude & 0.666 & $<0.0001$ & -0.621 & 0.001 & -0.410 & 0.047 & -0.659 & $<0.0001$ & 0.659 & $<0.0001$ & -0.620 & 0.001 & 0.620 & 0.001 \\
\hline & South latitude & 0.066 & 0.759 & 0.318 & 0.130 & 0.122 & 0.571 & -0.701 & $<0.0001$ & 0.701 & $<0.0001$ & -0.370 & 0.075 & 0.370 & 0.075 \\
\hline & Temperature & -0.664 & $<0.0001$ & 0.268 & 0.114 & 0.494 & 0.002 & 0.655 & $<0.0001$ & -0.655 & $<0.0001$ & 0.627 & $<0.0001$ & -0.627 & $<0.0001$ \\
\hline \multirow[t]{3}{*}{ Present Day } & Precipitation & -0.129 & 0.232 & -0.290 & 0.867 & -0.150 & 0.384 & -0.028 & 0.869 & 0.028 & 0.869 & 0.113 & 0.511 & -0.113 & 0.511 \\
\hline & Aridity & 0.286 & 0.007 & -0.201 & 0.24 & -0.267 & 0.116 & -0.185 & 0.279 & 0.185 & 0.279 & -0.029 & 0.868 & 0.029 & 0.868 \\
\hline & Temperature & -0.597 & $<0.0001$ & 0.216 & 0.207 & 0.342 & 0.041 & 0.560 & 0.0004 & -0.560 & 0.0003 & 0.635 & $<0.0001$ & -0.635 & $<0.0001$ \\
\hline \multirow[t]{3}{*}{ Holocene } & Precipitation & 0.072 & 0.510 & -0.235 & 0.167 & -0.522 & 0.001 & -0.381 & 0.022 & 0.381 & 0.022 & -0.190 & 0.266 & 0.190 & 0.266 \\
\hline & Aridity & 0.471 & $<0.0001$ & -0.344 & 0.04 & -0.575 & 0.0002 & -0.465 & 0.004 & 0.465 & 0.004 & -0.293 & 0.083 & 0.293 & 0.0832 \\
\hline & Temperature & -0.644 & $<0.0001$ & 0.297 & 0.079 & 0.608 & $<0.0001$ & 0.649 & $<0.0001$ & -0.649 & $<0.0001$ & 0.641 & $<0.0001$ & -0.641 & $<0.0001$ \\
\hline \multirow[t]{2}{*}{ Late Pleistocene } & Precipitation & 0.160 & 0.139 & -0.238 & 0.163 & -0.353 & 0.035 & -0.204 & 0.233 & 0.204 & 0.233 & -0.023 & 0.892 & 0.023 & 0.892 \\
\hline & Aridity & 0.532 & $<0.0001$ & -0.436 & 0.008 & -0.480 & 0.003 & -0.379 & 0.026 & 0.379 & 0.023 & -0.211 & 0.216 & 0.211 & 0.216 \\
\hline
\end{tabular}

For analyses with inferred CYP3A5 expression phenotypes high-, intermediate- and low- expression diplotypes were counted as genotypes and the frequencies of expresser and low/non-expresser alleles calculated. For analyses with phenotypes, African data genotyped for this study were tested. North latitude and south latitude correlations were only performed with populations genotyped for this study. 
Table 3 All polymorphic sites identified in an $8063 \mathrm{bp}$ CYP3A5 region re-sequenced in five Ethiopian populations

\begin{tabular}{|c|c|c|c|c|c|c|c|c|c|c|c|c|c|c|c|c|}
\hline \multirow[b]{2}{*}{ Region of CYP3A5 } & \multirow[b]{2}{*}{$\begin{array}{l}\text { Position on } \\
\text { chromosome } 7\end{array}$} & \multirow[b]{2}{*}{$\begin{array}{l}\text { Position relative to the translation } \\
\text { initiation codon (A of ATG is }+1 \text { ) }\end{array}$} & \multirow[b]{2}{*}{ dbSNP database refSNP ID } & \multirow[b]{2}{*}{ Effect } & \multicolumn{2}{|l|}{ Afar } & \multicolumn{2}{|c|}{ Amhara } & \multicolumn{2}{|c|}{ Anuak } & \multicolumn{2}{|c|}{ Maale } & \multicolumn{2}{|c|}{ Oromo } & \multicolumn{2}{|l|}{ Total } \\
\hline & & & & & $f$ & $\mathrm{n}$ & $f$ & $\mathrm{n}$ & $f$ & $\mathrm{n}$ & $f$ & $\mathrm{n}$ & $f$ & $\mathrm{n}$ & $f$ & $\mathrm{n}$ \\
\hline Promoter & 99278314 & $-795 \mathrm{~T}>\mathrm{A}$ & rs3823812 & & 0.00 & 3 & 0.00 & 3 & 0.01 & 4 & 0.01 & 10 & 0.01 & 5 & 0.0331 & 25 \\
\hline Promoter & 99278267 & $-748 \mathrm{C}>\mathrm{G}$ & & & 0.01 & 5 & 0.00 & 2 & 0.00 & 1 & 0.00 & 1 & 0.01 & 6 & 0.0198 & 15 \\
\hline Promoter & 99278224 & -705 3 base pair deletion & & & 0.00 & 1 & 0.00 & 1 & 0.01 & 5 & 0.00 & 1 & 0.00 & 3 & 0.0146 & 11 \\
\hline Promoter & 99278223 & $-704 A>G$ & & & 0.00 & 0 & 0.00 & 0 & 0.00 & 0 & 0.00 & 1 & 0.00 & 0 & 0.0013 & 1 \\
\hline Promoter & 99278152 & $-633 C>A$ & & & 0.00 & 0 & 0.00 & 0 & 0.00 & 0 & 0.00 & 0 & 0.00 & 1 & 0.0013 & 1 \\
\hline Promoter & 99278146 & $-627 \mathrm{G}>\mathrm{A}$ & & & 0.00 & 0 & 0.00 & 0 & 0.00 & 1 & 0.00 & 0 & 0.00 & 0 & 0.0013 & 1 \\
\hline Promoter & 99278144 & $-625 A>G$ & & & 0.00 & 0 & 0.00 & 0 & 0.00 & 0 & 0.00 & 1 & 0.00 & 0 & 0.0013 & 1 \\
\hline Promoter & 99278070 & $-551 \mathrm{C}>\mathrm{A}$ & rs28365079 & & 0.01 & 4 & 0.01 & 5 & 0.02 & 15 & 0.01 & 8 & 0.01 & 4 & 0.0476 & 36 \\
\hline Promoter & 99277988 & $-469 \mathrm{G}>\mathrm{A}$ & & & 0.00 & 0 & 0.00 & 0 & 0.00 & 0 & 0.00 & 1 & 0.00 & 0 & 0.0013 & 1 \\
\hline UTR of exon 1 & 99277593 & $-74 \mathrm{C}>\mathrm{T}$ & rs28371764 & & 0.00 & 2 & 0.01 & 6 & 0.00 & 0 & 0.00 & 2 & 0.00 & 2 & 0.0158 & 12 \\
\hline UTR of exon 1 & 99277544 & $-25 A>C$ & & & 0.00 & 0 & 0.00 & 0 & 0.00 & 0 & 0.00 & 0 & 0.00 & 1 & 0.0013 & 1 \\
\hline Intron 1 & 99277392 & $127 \mathrm{G}>\mathrm{A}$ & & & 0.00 & 0 & 0.00 & 0 & 0.00 & 1 & 0.00 & 2 & 0.00 & 0 & 0.0040 & 3 \\
\hline Intron 1 & 99277337 & $182 \mathrm{C}>\mathrm{A}$ & & & 0.00 & 0 & 0.00 & 0 & 0.00 & 3 & 0.00 & 0 & 0.00 & 0 & 0.0040 & 3 \\
\hline Intron 2 & 99272310 & 5209 C>T & rs 28365067 & & 0.01 & 11 & 0.02 & 12 & 0.01 & 5 & 0.01 & 8 & 0.01 & 8 & 0.0580 & 44 \\
\hline Intron 2 & 99272290 & $5229 \mathrm{G}>\mathrm{A}$ & rs41301652 & & 0.00 & 0 & 0.00 & 0 & 0.00 & 2 & 0.00 & 0 & 0.00 & 0 & 0.0026 & 2 \\
\hline Intron 2 & 99272275 & $5244 C>T$ & & & 0.00 & 0 & 0.00 & 0 & 0.00 & 0 & 0.00 & 0 & 0.00 & 2 & 0.0026 & 2 \\
\hline Intron 3 & 99272103 & $5416 C>T$ & & & 0.00 & 0 & 0.00 & 0 & 0.00 & 0 & 0.00 & 0 & 0.00 & 2 & 0.0026 & 2 \\
\hline Intron 3 & 99272009 & $5510 \mathrm{~T}>\mathrm{A}$ & rs28969392 & & 0.01 & 6 & 0.01 & 4 & 0.01 & 10 & 0.01 & 9 & 0.00 & 3 & 0.0422 & 32 \\
\hline Intron 3 & 99271928 & $5591 \mathrm{C}>\mathrm{T}$ & rs41301655 & & 0.00 & 0 & 0.01 & 4 & 0.00 & 1 & 0.00 & 0 & 0.00 & 2 & 0.0092 & 7 \\
\hline Intron 3 & 99271853 & $5666 A>G$ & rs41301658 & & 0.00 & 1 & 0.00 & 1 & 0.00 & 3 & 0.01 & 7 & 0.00 & 2 & 0.0185 & 14 \\
\hline Intron 3 & 99271808 & $5711 A>G$ & rs41258334 & & 0.01 & 11 & 0.01 & 11 & 0.01 & 5 & 0.01 & 9 & 0.01 & 8 & 0.0580 & 44 \\
\hline Intron 3 & 99271778 & $5741 A>G$ & & & 0.01 & 6 & 0.00 & 3 & 0.01 & 4 & 0.01 & 8 & 0.00 & 3 & 0.0317 & 24 \\
\hline Intron 3 & 99270539 & $6980 A>G$ & rs776746 & $\begin{array}{l}\text { Defines the } \\
\text { variant CYP3A5*3 }\end{array}$ & 0.13 & 95 & 0.14 & 102 & 0.06 & 44 & 0.10 & 75 & 0.13 & 97 & 0.5581 & 413 \\
\hline Intron 3 & 99270504 & 70153 base pair deletion & & & 0.00 & 0 & 0.00 & 0 & 0.00 & 0 & 0.00 & 1 & 0.00 & 0 & 0.0014 & 1 \\
\hline Intron 3 & 99270318 & $7201 \mathrm{C}>\mathrm{T}$ & rs8175345 & & 0.00 & 0 & 0.00 & 1 & 0.01 & 9 & 0.00 & 0 & 0.00 & 1 & 0.0149 & 11 \\
\hline Exon 4 & 99270249 & $7270 \mathrm{G}>\mathrm{A}$ & & G77S & 0.00 & 0 & 0.00 & 0 & 0.00 & 0 & 0.00 & 1 & 0.00 & 0 & 0.0014 & 1 \\
\hline Intron 4 & 99270164 & 7355 C>T & rs 28365074 & & 0.00 & 0 & 0.00 & 0 & 0.00 & 1 & 0.00 & 0 & 0.00 & 2 & 0.0041 & 3 \\
\hline Intron 5 & 99264352 & $13167 \mathrm{~T}>\mathrm{C}$ & rs68178885 & & 0.00 & 3 & 0.00 & 2 & 0.00 & 1 & 0.00 & 3 & 0.00 & 1 & 0.0132 & 10 \\
\hline Intron 6 & 99264149 & $13370 \mathrm{G}>\mathrm{A}$ & rs41301670 & & 0.00 & 0 & 0.00 & 0 & 0.00 & 0 & 0.00 & 0 & 0.00 & 2 & 0.0027 & 2 \\
\hline Exon 7 & 99262835 & $14684 \mathrm{G}>\mathrm{A}$ & rs 10264272 & $\begin{array}{l}\text { Defines the } \\
\text { variant CYP3A5*6 }\end{array}$ & 0.04 & 28 & 0.03 & 23 & 0.05 & 39 & 0.03 & 23 & 0.03 & 21 & 0.1763 & 134 \\
\hline
\end{tabular}


Table 3 All polymorphic sites identified in an $8063 \mathrm{bp}$ CYP3A5 region re-sequenced in five Ethiopian populations (Continued)

\begin{tabular}{|c|c|c|c|c|c|c|c|c|c|c|c|c|c|c|c|c|}
\hline Exon 7 & 99262793 & $14726 A>G$ & rs2838372 & Synonymous & 0.00 & 1 & 0.00 & 0 & 0.00 & 0 & 0.00 & 0 & 0.00 & 0 & 0.0013 & 1 \\
\hline Intron 7 & 99262642 & $14877 A>G$ & & & 0.00 & 1 & 0.01 & 5 & 0.02 & 12 & 0.01 & 9 & 0.00 & 2 & 0.0382 & 29 \\
\hline Intron 7 & 99261737 & $15782 \mathrm{~T}>C$ & rs28969393 & & 0.01 & 5 & 0.01 & 4 & 0.01 & 9 & 0.01 & 9 & 0.00 & 3 & 0.0396 & 30 \\
\hline Exon 8 & 99261651 & $15868 A>G$ & & K266R & 0.00 & 0 & 0.00 & 0 & 0.00 & 1 & 0.00 & 0 & 0.00 & 0 & 0.0013 & 1 \\
\hline Intron 8 & 99261583 & $15936 C>A$ & & & 0.00 & 0 & 0.00 & 0 & 0.00 & 0 & 0.00 & 2 & 0.00 & 0 & 0.0026 & 2 \\
\hline Intron 8 & 99260546 & 16973 G>A & & & 0.00 & 0 & 0.00 & 1 & 0.00 & 0 & 0.00 & 0 & 0.00 & 0 & 0.0013 & 1 \\
\hline Exon 9 & 99260502 & 17017 C>T & & R268Stop & 0.00 & 0 & 0.00 & 0 & 0.00 & 1 & 0.00 & 0 & 0.00 & 0 & 0.0013 & 1 \\
\hline Intron 9 & 99260407 & $17112 \mathrm{C}>\mathrm{T}$ & rs28383478 & & 0.00 & 0 & 0.00 & 2 & 0.00 & 0 & 0.00 & 0 & 0.00 & 0 & 0.0026 & 2 \\
\hline Intron 9 & 99260362 & 17157 G>T & rs4646453 & & 0.00 & 3 & 0.00 & 3 & 0.01 & 4 & 0.01 & 10 & 0.01 & 5 & 0.0331 & 25 \\
\hline Intron 9 & 99260282 & $17237 \mathrm{~T}>\mathrm{G}$ & & & 0.00 & 0 & 0.00 & 0 & 0.00 & 1 & 0.00 & 0 & 0.00 & 0 & 0.0013 & 1 \\
\hline Intron 9 & 99260170 & $17349 \mathrm{~T}>\mathrm{G}$ & & & 0.00 & 3 & 0.00 & 2 & 0.01 & 7 & 0.01 & 7 & 0.00 & 3 & 0.0291 & 22 \\
\hline Intron 9 & 99258524 & $18995 \mathrm{C}>\mathrm{T}$ & rs10247580 & & 0.00 & 0 & 0.00 & 2 & 0.02 & 12 & 0.01 & 7 & 0.00 & 1 & 0.0291 & 22 \\
\hline Intron 9 & 99258320 & $19199 \mathrm{G}>\mathrm{A}$ & & & 0.00 & 0 & 0.00 & 0 & 0.00 & 1 & 0.00 & 0 & 0.00 & 0 & 0.0013 & 1 \\
\hline Intron 9 & 99258316 & $19203 \mathrm{~T}>\mathrm{C}$ & & & 0.00 & 0 & 0.00 & 0 & 0.00 & 0 & 0.00 & 2 & 0.00 & 0 & 0.0026 & 2 \\
\hline Exon 10 & 99258124 & $19395 A>C$ & & K342T & 0.00 & 0 & 0.00 & 0 & 0.00 & 0 & 0.00 & 0 & 0.00 & 1 & 0.0013 & 1 \\
\hline Exon 11 & 99250397 & 27125-27126 T insertion & rs41303343 & $\begin{array}{l}\text { Defines the } \\
\text { variant CYP } 3 A 5^{*} 7\end{array}$ & 0.00 & 0 & 0.00 & 0 & 0.00 & 1 & 0.00 & 1 & 0.00 & 0 & 0.0026 & 2 \\
\hline Exon 11 & 99250381 & $27138 A>G$ & & V350M & 0.00 & 0 & 0.00 & 0 & 0.00 & 1 & 0.00 & 0 & 0.00 & 0 & 0.0013 & 1 \\
\hline Intron 12 & 99247647 & 29872 G>T & & & 0.00 & 0 & 0.00 & 0 & 0.00 & 0 & 0.00 & 2 & 0.00 & 0 & 0.0026 & 2 \\
\hline Intron 12 & 99247503 & 300161 base pair deletion & rs28365093 & & 0.00 & 3 & 0.01 & 4 & 0.02 & 15 & 0.01 & 8 & 0.01 & 4 & 0.0450 & 34 \\
\hline Intron 12 & 99246026 & $31493 \mathrm{~T}>\mathrm{C}$ & rs28365069 & & 0.01 & 4 & 0.01 & 11 & 0.01 & 11 & 0.02 & 18 & 0.01 & 9 & 0.0699 & 53 \\
\hline 3' UTR & 99245914 & $31605 C>T$ & rs15524 & & 0.14 & 105 & 0.14 & 109 & 0.09 & 69 & 0.11 & 84 & 0.14 & 107 & 0.6253 & 474 \\
\hline
\end{tabular}


more detailed surveys of clinically important variation in diverse African populations will improve our understanding of how specific drugs and dosages contribute to adverse clinical outcomes within Africa and the African Diaspora. The number of such studies will undoubtedly increase with the availability of newer and cheaper sequencing technologies [58,59] and progression towards the $\$ 1000$ genome [60].

We combined our African CYP $3 A 5 * 3$ data with those previously published to examine the global prevalence of the allele. We found a significant, positive correlation between $C Y P 3 A 5 * 3$ allele frequencies and latitude, consistent with a previous report [20]. This correlation remained significant when only African data were considered [Spearmann Rho $=0.666, p<0.0001$ ]. In contrast we found no significant correlation between latitude and $C Y P 3 A 5 * 6$ or $C Y P 3 A 5 * 7$ frequencies. Given the restricted geographic distribution of the $C Y P 3 A 5 \% 6$ allele mainly to Africa, coupled with our estimates of its age (>200,000 years), it is possible that this allele was lost in a population bottleneck during the range-expansion of humans out of Africa. The heterogeneous distribution of $C Y P 3 A 5 * 7$ in Africa suggests that it arose from a much more recent mutation event and may have spread with the expansion of Niger-Congo speaking populations $\sim 4000$ years ago [61]. Nonetheless, the reasons why the derived $C Y P 3 A 5 * 3, C Y P 3 A 5 * 6$ and $C Y P 3 A 5 * 7$ alleles are found at appreciable frequencies in sub-Saharan Africa remains unknown, and the possibility of independent evolutionary causes cannot be discounted. The global distribution of the $C Y P 3 A 5 * 3$ allele is unusual when compared with microsatellite markers, genotyped in samples from the Human Genome Diversity Panel (HDGP-CEPH) [20]. Integrated haplotype scores (iHS) for $C Y P 3 A 5 * 3$ haplotypes in HGDP-CEPH populations sampled from high latitudes north and south of the equator are outliers in the iHS genome-wide distribution ( $\mathrm{iHS} \geq 2$ ) [62]. iHS scores of $C Y P 3 A 5^{*} 3$ haplotypes are similar to those of genomic regions surrounding the LCT (lactase) and CD36 genes [63], which have both been reported to have undergone positive selection [64-66]. It is plausible that an increase in latitude of $\sim 20^{\circ}$, when humans first expanded from East Africa to the Arabian Peninsula, is coupled with specific environmental changes which provided a novel selection pressure. Temperature and precipitation data associated with the Quaternary QUEST project (accessed through the British Atmospheric Centre: http://badc.nerc.ac.uk/home/index. html) suggest that changes in precipitation over the past 50,000 years are greater than those in temperature. However we did not find any significant correlation between precipitation values and CYP $3 A 5$ allele frequencies. We did observe negative correlations between inferred expression phenotypes (assuming CYP3A5*6 is a low/non-expresser allele) and aridity values for the Holocene [Spearmann's Rho $=-0.465, p=0.004$ ] and Late Pleistocene [Spearmann's Rho $=-0.379, p=0.02]$. Under the de Martonne aridity index, this means that high frequencies of high-activity alleles are positively correlated with arid and semi-arid environments [34]. This finding is consistent with the hypothesis that high-activity CYP3A5 alleles may be adaptive in regions where there are frequent water shortages, by aiding the rapid retention of water [20]. However, stronger correlations were found with temperature alone. Although further work will be needed to confirm these ecological correlations, the strong correlation with temperature is consistent with what we would expect for functional variation of genes involved in heat adaptation [21]. However, we cannot rule out that there may be an, as yet untested, ecological variable which may have provided a selective pressure.

We have provided the first estimate of the age of the CYP3A5*3 allele as $\sim 76,000$ years (95\% C.I. $57,504-$

Table 4 A summary of the tests for departures from neutrality for an 8063bp region of CYP3A5

\begin{tabular}{|c|c|c|c|c|c|c|c|c|}
\hline & \multicolumn{3}{|l|}{ Global populations } & \multicolumn{5}{|c|}{ Ethiopian populations } \\
\hline & African-Americans & Europeans & Han Chinese & Afar & Amhara & Anuak & Maale & Oromo \\
\hline Sample size & 23 & 24 & 23 & 75 & 76 & 76 & 76 & 76 \\
\hline Nucleotide diversity $(\pi)$ & $5.4 \times 10^{-4}$ & $9 \times 10^{-5}$ & $1.1 \times 10^{-4}$ & $2.1 \times 10^{-4}$ & $2.5 \times 10^{-4}$ & $3.6 \times 10^{-4}$ & $3.5 \times 10^{-4}$ & $2.2 \times 10^{-4}$ \\
\hline McDonald-Kreitman test & 0.475 & 0.50 & 0.777 & 0.462 & 0.475 & 0.576 & 1.00 & 0.777 \\
\hline Tajima's $D$ & -1.04 & -1.92 & -1.21 & -1.46 & -1.13 & -1.26 & -0.96 & -1.79 \\
\hline Fu and Li's $D^{*}$ & -0.97 & -2.86 & -1.82 & -1.19 & 0.12 & -2.72 & -0.11 & -1.05 \\
\hline Fu and Li's $F^{*}$ & -1.17 & -3.00 & -1.91 & -1.54 & -0.43 & -2.57 & -0.53 & -1.58 \\
\hline Fu and Li's $D$ & -0.64 & -1.37 & -1.45 & -1.56 & -0.08 & -1.93 & 0.73 & -0.96 \\
\hline Fu and Li's $F$ & -0.92 & -1.81 & -1.55 & -1.79 & -0.52 & -1.96 & 0.13 & -1.48 \\
\hline Fu's $F_{S}$ & -31.06 & -5.71 & -1.54 & -9.48 & -11.74 & -18.44 & -11.08 & -22.84 \\
\hline Strobeck's S & 1.00 & 0.999 & 0.929 & 1.00 & 1.00 & 1.00 & 1.00 & 1.00 \\
\hline Fay and Wu's $H$ statistic & -0.13140 & -3.25532 & -1.89372 & 0.10774 & -0.23998 & -0.47177 & -0.87086 & -1.75514 \\
\hline
\end{tabular}




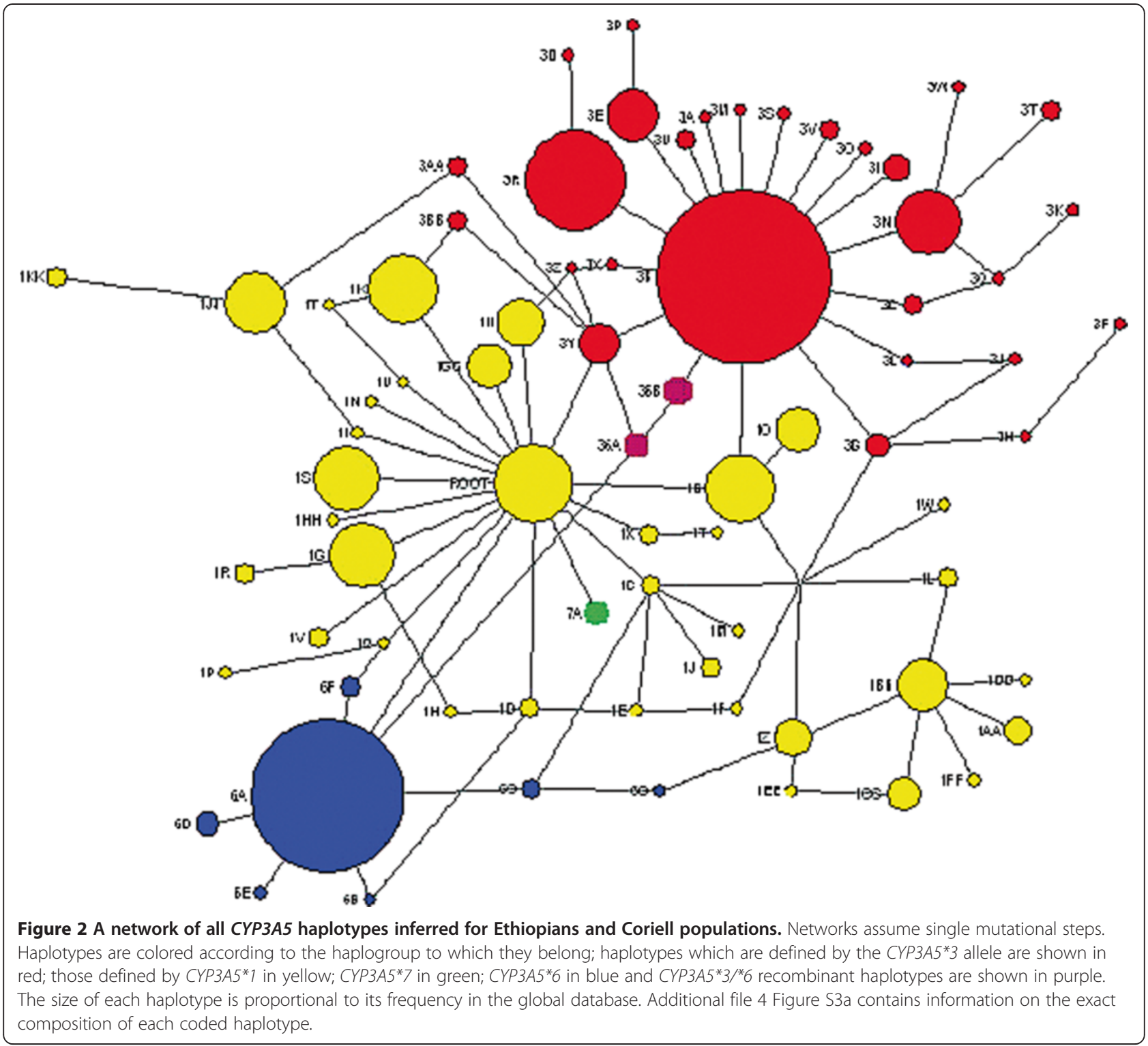

102,752 years), using a closely linked microsatellite. This estimate is consistent with the wide geographic distribution of $C Y P 3 A 5 * 3$, both inside and outside Africa although not with the low haplotype diversity $[20,67]$ and high iHS scores [62] previously reported. This may be because the allele age estimation presented here was made using Ethiopian data whereas the previously reported low haplotype diversity [20,67] and high iHS scores [62] were based on non-African samples. It is also possible that the microsatellite mutation rate for rs10536492 differs from the genome wide average for dinucleotide repeats [68], which would influence the age estimates, or that the extensive LD on haplotypes containing $C Y P 3 A 5 \% 3$ is explained by unusually low recombination rates in that genomic region. Finally, while the correlations between the $C Y P 3 A 5 * 3$ geographic distribution and ecological variables relating to temperature and aridity, as well as previously reported low haplotype diversity [20,67] and high iHS scores [62], both independently support the hypothesis that the $C Y P 3 A 5 * 3$ allele is adaptive, alternative targets of positive selection on the same haplotype background may exist and both they (if present) and the $C Y P 3 A 5 * 3$ allele may have been differentially selected inside and outside Africa.

\section{Conclusions}

The data that we present complement and extend work in previous publications which reported evidence of geographically restricted positive selection on the CYP3A5 gene $[20,25,26,69]$. In addition to improved knowledge of the effect and distribution of clinically relevant genetic variation, our approach highlights the importance of 
considering population history and of utilizing evolutionary approaches in clinical research. Evolutionary approaches to genetic studies are likely to identify additional populations that require targeted health interventions. Further studies which characterize variation in medically important genes in ethnically and geographically diverse global populations are needed as we progress towards personalized clinical medicine, a key goal of the genomics revolution [70].

\section{Methods \\ Samples}

The DNA samples analyzed in this study were part of a collection at The Centre for Genetic Anthropology at University College London. Samples were collected anonymously and with informed consent (verbal in Africa) from ostensibly healthy individuals, between 1998-2007, from specified locations in and around Africa [ethical approval: UCLH 99/0196]. Additional ethical approval was obtained for Ethiopian collections from the National Health Research Ethical Clearance Committee under the Ethiopian Science and Technology Commission in Addis Ababa. All samples have been previously used in studies on clinically relevant genes [31-33]. For analyses, individuals were grouped by the collection location or by ethnicity (Additional file 5 Table S2). Samples were not grouped according to country as the partitioning of much of the African continent by colonial powers was recent and largely irrespective of ethnic identities [71]. 1028 CYP $3 A 5 * 1 / * 3$ genotypes for 51 global populations, from the Human Genome Diversity Panel-Centre d'Etude du Polymorphisme Humain (HGDP-CEPH) collection, which had previously been published [20] were combined with the 2538 sample cohort genotyped for this study. CYP $3 A 5$ re-sequencing data, which were previously published, for 70 individuals from three distinct ethnic groups from the Coriell Repositories (24 European Caucasians, 23 African-Americans and 23 Han Chinese individuals) were combined with the Ethiopian cohort for detailed integrative analyses [20].
Published data were provided by Dr Emma Thompson from the University of Chicago.

\section{Genotyping and re-sequencing}

Genotyping of clinically relevant CYP3A5 alleles; Genotyping of $C Y P 3 A 5 * 1, C Y P 3 A 5 * 3, C Y P 3 A 5 * 6$ and $C Y P 3 A 5 * 7$ was performed using TaqMAN allelic discrimination technology [ABiosystems product code: C_26201809_30 for $C Y P 3 A 5^{*} 1 / 3$, and ABiosystems product code: C_30203959 for CYP3A5\%6], and KASPar (performed externally by KBiosciences ${ }^{\oplus}$ UK).

Re-sequencing of CYP3A5; The 13 exons and their flanking introns, promoter region and 3' untranslated of CYP3A5 were amplified in 379 Ethiopian individuals using primers designed on the basis of the CYP3A5 reference sequence in NCBI Build 132 [(http://www.ncbi.nlm.nih.gov/) (see Additional file 6 Table S3 for a list of primers)]. Amplicons were sequenced using ABI PRISM Dye Terminators version 3.1 on an ABI 96-capillary $3730 \times 1$ DNA Analyzer according to the manufacturer's protocol (Applied Biosystems, Applera, UK). Part of the CYP3A5 gene was resequenced externally by Macrogen ${ }^{\oplus}$, USA.

Microsatellite genotyping; A -GT microsatellite, located $\sim 1500$ base pairs downstream of the $3^{\prime}$ end of CYP3A5 was genotyped in 379 Ethiopian individuals, for whom re-sequencing data were also generated. Microsatellite genotyping was performed using a high-throughput method adapted from [72]. A 456 base pair region of CYP3A5, approximately $\sim 1000$ base pairs downstream of the 3' UTR was amplified using the forward primer $5^{\prime}$ AATATATGTGTTTGTATGTGTG-3' and a fluorescently labeled reverse primer FAM-AAGTGCTACCAATTTTGT ACGT-3'. PCR amplification was performed in $10 \mu \mathrm{l}$ reaction volumes containing 1 ng of template DNA, $0.5 \mu \mathrm{M}$ of primers, 0.2 units Taq DNA polymerase (HT Biotech, Cambridge, UK), $0.2 \mu \mathrm{mol}$ dNTPs, $0.1 \mu \mathrm{mol}$ of 10X Buffer IV (Thermo Scientific ${ }^{\circledR}$ ) and $0.28 \mu \mathrm{l}$ of magnesium chloride (concentration $25 \mathrm{mM}$ ). Cycling conditions were 5 minutes of pre-incubation at $95^{\circ} \mathrm{C}$, followed by 38 cycles of $95^{\circ} \mathrm{C}$ for one minute, $58^{\circ} \mathrm{C}$ for 40 seconds, $72^{\circ} \mathrm{C}$ for 40 seconds, with

Table 5 Pairwise $\boldsymbol{F}_{\mathrm{ST}}$ values for five Ethiopian populations and three other global populations

\begin{tabular}{|c|c|c|c|c|c|c|c|c|}
\hline & Afar & Amhara & Anuak & Maale & Oromo & African-Americans & Europeans & Han Chinese \\
\hline Afar & * & 0.74597 & $<0.00001$ & 0.00436 & 0.76537 & $<0.00001$ & $<0.00001$ & $<0.00001$ \\
\hline Amhara & -0.00248 & * & $<0.00001$ & 0.00347 & 0.93525 & $<0.00001$ & $<0.00001$ & $<0.00001$ \\
\hline Anuak & 0.04566 & 0.05138 & $*$ & 0.00257 & $<0.00001$ & $<0.00001$ & $<0.00001$ & $<0.00001$ \\
\hline Maale & 0.01951 & 0.01736 & 0.01061 & $*$ & 0.00267 & $<0.00001$ & $<0.00001$ & $<0.00001$ \\
\hline Oromo & -0.00255 & -0.0036 & 0.04981 & 0.01547 & * & $<0.00001$ & $<0.00001$ & $<0.00001$ \\
\hline African-Americans & 0.08997 & 0.09366 & 0.01558 & 0.03432 & 0.08803 & * & $<0.00001$ & $<0.00001$ \\
\hline Europeans & 0.04873 & 0.03807 & 0.15448 & 0.08716 & 0.03371 & 0.19028 & * & 0.00257 \\
\hline Han Chinese & 0.10812 & 0.0893 & 0.23763 & 0.16215 & 0.09715 & 0.29154 & 0.0677 & * \\
\hline
\end{tabular}

Pairwise $F_{\mathrm{ST}}$ values are shown in the bottom left side of the Table, the corresponding $p$-values are shown in the top right of the Table. $P$-values which are significant after Bonferroni correction (adjusted $p$-value $=0.00625$; correction for 8 tests) are shown in bold. 
Table 6 Age estimates of clinically relevant CYP3A5 variants

\begin{tabular}{|c|c|c|c|c|c|c|c|c|c|c|c|}
\hline \multirow[t]{3}{*}{$\begin{array}{l}\text { CYP3A5 } \\
\text { variant }\end{array}$} & \multirow[t]{3}{*}{$\begin{array}{l}\text { Location on } \\
\text { chromosome } 7\end{array}$} & \multirow[t]{3}{*}{$\begin{array}{l}\text { Location } \\
\text { in gene }\end{array}$} & \multirow[t]{3}{*}{$\begin{array}{l}\text { Allele } \\
\text { dated }\end{array}$} & \multirow[t]{3}{*}{$\begin{array}{l}\text { Number of } \\
\text { chromosomes }\end{array}$} & \multirow{3}{*}{$\begin{array}{l}\text { Average } \\
\text { squared } \\
\text { distance } \\
\text { (ASD) }\end{array}$} & \multicolumn{2}{|c|}{$\begin{array}{l}\text { Time to most recent } \\
\text { common ancestor }\end{array}$} & \multicolumn{4}{|c|}{$\begin{array}{l}\text { 95\% confidence intervals of allele age } \\
\text { estimate based on a star phylogeny }\end{array}$} \\
\hline & & & & & & \multicolumn{2}{|c|}{$\begin{array}{l}\text { Estimate of } \\
\text { allele age }\end{array}$} & \multicolumn{2}{|c|}{ Lower } & \multicolumn{2}{|c|}{ Upper } \\
\hline & & & & & & Generations & Years & Generations & Years & Generations & Years \\
\hline CYP $3 A 5 * 3$ & 99270539 & Intron 3 & G & 134 & 1.0746 & 2388 & 76,416 & 1797 & 57,504 & 3211 & 102,752 \\
\hline CYP $3 A 5 * 6$ & 99262835 & Exon 7 & A & 18 & 3.0714 & 6825 & 218,400 & 3086 & 98.752 & 11975 & 383,200 \\
\hline rs15524 & 99245914 & 3' UTR & $\mathrm{T}$ & 324 & 1.8426 & 4095 & 131,040 & 3157 & 101,024 & 5413 & 173,216 \\
\hline
\end{tabular}

Allele ages were estimated using a mutation rate of 0.00045 and a generation time of 32 years. The confidence intervals for the estimated age of the CYP3A5*6 are large; most likely a reflection of the small sample size. UTR is the Untranslated Region.

a final elongation step at $72^{\circ} \mathrm{C}$ for 10 minutes. Following amplification, a $1.1 \mu \mathrm{l}$ aliquot of amplified PCR product was added to $9.89 \mu \mathrm{l}$ of high purity (HiDi) formamide and $0.11 \mu \mathrm{l}$ of ROX-500 size standard (Applied Biosystems, Warrington, UK). Samples were run on an $\times 3730$ DNA Analyzer and analyzed using GeneMapper 4 software (Applied Biosystems, Warrington UK).

\section{Data analyses}

Molecular diversity and Population genetics; exact tests of deviation from Hardy-Weinberg equilibrium (using 10,000 steps in a Markov chain), pairwise $F_{\mathrm{ST}}$, and AMOVA, were all performed using Arlequin 3.5 [73]. Pairwise $F_{\mathrm{ST}}$ estimates were used to perform principal co-ordinates analysis in the R-programming environment using routines in the APE package. The $D^{\prime}$ measure of linkage disequilibrium was calculated using the expectation maximization algorithm using LDMax (part of the GOLD software package, freely available at: http://www. sph.umich.edu/csg/abecasis/GOLD/docs/ldmax.html).

Haplotypes were inferred using PHASE version 2.1 (1000 iterations, 500 burn-in) [74]. Singletons were removed for haplotype and LD analysis. Haplotype networks were constructed using a median-joining network implemented in Network 4.6.1 and re-colored using Adobe PhotoShop CS4. Nucleotide diversity, tests for departures from neutrality, Fay and Wu's $\mathrm{H}$ test and the HKA test were all performed using DnaSP 5.0 [75]. The chimpanzee CYP3A5 gene sequence was downloaded from NCBI (http://www. ncbi.nlm.nih.gov/).

Ecological correlations; geographic co-ordinates were used to calculate distance from the equator (in kilometers) using the online programme: http://www.movabletype.co.uk/scripts/latlong.html. Raw ecological data for temperature (in degrees Celsius) and precipitation (in $\mathrm{mm})$, at each set of geographic co-ordinates, for 0 , 10,000 and 50,000 years ago were extracted from the British Atmospheric Data Centre (http://badc.nerc.ac. uk/home/index.html), from the ALL-5G dataset associated with the Quaternary QUEST (http:// researchpages.net/QQ/) [76]. The data were extracted using Python. The raw data have a resolution of $5 \mathrm{de}-$ grees latitude and 7.5 degrees longitude and were interpolated to a resolution of 1 degree latitude and 1 degree longitude. The interpolations were done using the smooth.2d function in the fields library of the Rprogramming environment. An estimate of relative aridity was inferred from extracted temperature and precipitation values corresponding to each geographic location using the de Martonne aridity index [34]. Mantel and partial Mantel tests were performed in the R-programming environment using routines in the APE package [77] and ecodist package [78] respectively.

Bioinformatics analyses of genetic variation on protein expression and function; cross-species alignments of CYP3A5 orthologues (sequences obtained from NCBI: http://www.ncbi.nlm.nih.gov/) were performed using ClustalW software (http://www.ebi.ac.uk/Tools/msa/ clustalw2/). Analyses of regulatory motifs in the CYP3A5 promoter were performed using MatInspector [79], effects of amino acid substitutions on the structure and function of CYP3A5 were performed using PolyPhen2 [80], predictions of mutations which are likely to affect gene splicing were performed using the online Berkeley Drosophila Genome Project splice predictor [81].

Estimating the age of the clinically relevant CYP3A5 variants; The gametic phase of CYP3A5 mutations and the -GT microsatellite (rs10536492) was not determined empirically. Allele ages were estimated using data for individuals homozygous for particular haplotypes. As no Ethiopian individual was identified to be a $C Y P 3 A 5 \% 7$ homozygote, this variant could not be dated. Under the stepwise mutation model the variance (ASD) in the microsatellite repeat length, from the most recent common ancestor, is a linear function of the mutation rate $(\mu)$ and coalescence time in generations $(t) ; A S D=\mu t$ $[82,83]$. A mutation rate of $4.5 \times 10^{-4}$ was used to estimate the time to the most recent common ancestor (MRCA) 
based on average estimates of the mutation rate of dinucleotide microsatellites in the human genome $[68,84]$.

ASD and $t$ were calculated using Ytime software [85]. The microsatellite length of the ancestral MRCA is assumed to be known. For this study the ancestral length of the microsatellite was estimated to be 35 ; as the majority of CYP $3 A 5 * 1$ haplotypes had 35 repeats. Confidence intervals for the age estimates were obtained from calculating the distances between the ancestral and derived chromosomes under a star-genealogy model; based on the results of network analysis of CYP3A5 haplotypes. A generation was assumed to be 32 years [46].

\section{Additional files}

Additional file 1: Table S1. "The proportion of each inferred CYP3A5 haplotype observed in each population." The Table lists the frequencies of each inferred CYP3A5 haplotype, by population.

Additional file 2: Figure S1. "The distribution of high-, intermediateand low- CYP3A5 expression phenotypes, inferred from diplotypes." The Figure shows inferred CYP3A5 expression phenotypes, assuming that CYP3A5*6 causes low/non-expression of CYP3A5. The size of each circle is proportional to the number of individuals sampled from a given population (see Additional file Table S1).

Additional file 3: Figure S2. "The distribution of high-, intermediateand low- CYP3A5 expression phenotypes, inferred from diplotypes." The Figure shows inferred CYP3A5 expression phenotypes, assuming that CYP3A5*6 does not cause low/non-expression of CYP3A5. The size of each circle is proportional to the number of individuals sampled from a given population (see Additional file Table S1).

Additional file 4: Figures S3a and b. "Haplotypes inferred from genotype data in 8 populations." Supplementary Figure 3a shows the composition of each CYP3A5 haplotype inferred from genotype data for 8 global populations. The frequencies of each haplotype, by population, are shown in Additional file Figure S3b.

Additional file 5: Table S2. "Geographic co-ordinates, sample size and major language family of each population genotyped in the geographic survey of clinically relevant CYP3A5 alleles. The CYP3A5 gene was resequenced in five Ethiopian populations." This Table provides details of all populations which were genotyped, and re-sequenced for this study.

Additional file 6: Table S3. "A list of the primers used for PCR amplification and sequencing of CYP3A5."

\section{Competing interest}

Neil Bradman is Chairman of The Henry Stewart Group and London and City Group of Companies and has extensive business and financial interests including involvement in biotechnology ventures and educational material used by researchers in the life sciences. The research has been funded in part by the London and City Group of Companies and the Melford Charitable Trust of which Neil Bradman is a trustee. The Melford Charitable Trust, London and City Group of Companies and Neil Bradman do have any intellectual, or other, property rights whatsoever with respect to the research which forms the subject matter of the paper. All other authors have no conflict of interest.

\section{Authors' contributions}

RKB carried out the molecular genetic studies, analyses of data and drafted the manuscript. MK extracted and interpolated all climate data from the British Atmospheric Survey. CAP performed genotyping of the Hypervariable Segment 1 and the Y-chromosome in Ethiopian populations. AT and EB collected all Ethiopian samples which were used for analysis within this study. NNB assisted with the collection of most African samples used in this study, and conceived the initial experimental design of the project. MGT conceived the statistical analyses of the project, in particular those relating to ecological data, and oversaw the writing of the manuscript. All authors read and approved the final manuscript.

\section{Acknowledgements}

The authors wish to thank Professor Andrés Ruiz-Linares for help and guidance with the analyses, as well as Professor Dallas Swallow, Mr. Victor Acuña-Alonso, and Mr. Pawel Zmarz for helpful discussion of the manuscript, and Dr Emma Thompson for providing CYP3A5*3 genotypes and CYP3A5 re-sequencing data for combined analyses. Additional thanks to Ranji Arasaretnam, Mari-Wyn Burley and Rosemary Ekong for help with DNA extractions and sequencing. This work was supported by a Biotechnology and Biological Sciences Research Council-CASE Ph. D. studentship, funding from the London and City Group of Companies and the Melford Charitable Trust [which were awarded to Ripudaman K Bains], and funding from the Engineering and Physical Sciences Research Council [which was awarded to Mirna Kovacevic through UCL CoMPLEX].

\section{Author details}

${ }^{1}$ Research Department of Genetics, Evolution and Environment, University College London, Darwin Building, Gower Street, London WC1E 6BT, UK. ${ }^{2}$ Centre for Mathematics and Physics in the Life Sciences and Experimental Biology (CoMPLEX), University College London, Physics Building, Gower Street, London WC1E 6BT, UK. ${ }^{3}$ Addis Ababa University and Center of Human Genetic Diversity, P.O. Box 1176, Addis Ababa, Ethiopia. ${ }^{4}$ Henry Stewart Group, 28/30 Little Russell Street, London WC1A 2HN, UK. ${ }^{5}$ Department of Evolutionary Biology, Uppsala University, Uppsala, Sweden.

Received: 15 February 2013 Accepted: 25 April 2013

Published: 3 May 2013

\section{References}

1. Coleman R: Disease burden in sub-Saharan Africa. Lancet 1998, 351(9110):1208.

2. Stearns SC: Evolutionary medicine: its scope, interest and potential. Proceedings Biological sciences/The Royal Society 2012, 279(1746):4305-4321

3. Zhou SF, Liu JP, Chowbay B: Polymorphism of human cytochrome P450 enzymes and its clinical impact. Drug Metab Rev 2009, 41(2):89-295.

4. Nebert DW, Russell DW: Clinical importance of the cytochromes P450. Lancet 2002, 360(9340):1155-1162.

5. Wojnowski L: Genetics of the variable expression of CYP3A in humans. Ther Drug Monit 2004, 26(2):192-199.

6. Perera MA: The missing linkage: what pharmacogenetic associations are left to find in CYP3A? Expert Opin Drug Metab Toxicol 2010, 6(1):17-28.

7. Shi Y, Li Y, Tang J, Zhang J, Zou Y, Cai B, Wang L: Influence of CYP3A4, CYP3A5 and MDR-1 polymorphisms on tacrolimus pharmacokinetics and early renal dysfunction in liver transplant recipients. Gene 2013, 512(2):226-231.

8. Bochud M, Eap CB, Elston RC, Bovet P, Maillard M, Schild L, Shamlaye C, Burnier M: Association of CYP3A5 genotypes with blood pressure and renal function in African families.J Hypertens 2006, 24(5):923-929.

9. Plummer SJ, Conti DV, Paris PL, Curran AP, Casey G, Witte JS: CYP3A4 and CYP3A5 genotypes, haplotypes, and risk of prostate cancer. Canc Epidemiol Biomarkers Prev: a publication of the American Association for Cancer Research, cosponsored by the American Society of Preventive Oncology 2003, 12(9):928-932.

10. Lee SJ, Usmani KA, Chanas B, Ghanayem B, Xi T, Hodgson E, Mohrenweiser $H W$, Goldstein JA: Genetic findings and functional studies of human CYP3A5 single nucleotide polymorphisms in different ethnic groups. Pharmacogenetics 2003, 13(8):461-472.

11. Aoyama T, Yamano S, Waxman DJ, Lapenson DP, Meyer UA, Fischer $V$, Tyndale R, Inaba T, Kalow W, Gelboin HV: Cytochrome P-450 hPCN3, a novel cytochrome P-450 IIIA gene product that is differentially expressed in adult human liver. CDNA and deduced amino acid sequence and distinct specificities of CDNA-expressed hPCN1 and hPCN3 for the metabolism of steroid hormones and cyclosporine. J Biol Chem 1989, 264(18):10388-10395.

12. Schuetz JD, Molowa DT, Guzelian PS: Characterization of a cDNA encoding a new member of the glucocorticoid-responsive cytochromes P450 in human liver. Arch Biochem Biophys 1989, 274(2):355-365.

13. Kuehl P, Zhang J, Lin Y, Lamba J, Assem M, Schuetz J, Watkins PB, Daly A, Wrighton SA, Hall SD, Maurel P, Relling M, Brimer C, Yasuda K, Venkataramanan R, Strom S, Thummel K, Boguski MS, Schuetz E: Sequence 
diversity in CYP3A promoters and characterization of the genetic basis of polymorphic CYP3A5 expression. Nat Genet 2001, 27(4):383-391.

14. Hustert E, Haberl M, Burk O, Wolbold R, He YQ, Klein K, Nuessler AC, Neuhaus P, Klattig J, Eiselt R, Koch I, Zibat A, Brockmoller J, Halpert JR, Zanger UM, Wojnowski L: The genetic determinants of the CYP3A5 polymorphism. Pharmacogenetics 2001, 11(9):773-779.

15. Quaranta S, Chevalier D, Allorge D, Lo-Guidice JM, Migot-Nabias F, Kenani A, Imbenotte M, Broly F, Lacarelle B, Lhermitte M: Ethnic differences in the distribution of CYP3A5 gene polymorphisms. Xenobiotica 2006, 36(12):1191-1200.

16. Roy JN, Lajoie J, Zijenah LS, Barama A, Poirier C, Ward BJ, Roger M: CYP3A5 genetic polymorphisms in different ethnic populations. Drug Metab Dispos 2005, 33(7):884-887.

17. Park SY, Kang YS, Jeong MS, Yoon HK, Han KO: Frequencies of CYP3A5 genotypes and haplotypes in a Korean population. J Clin Pharm Ther 2008, 33(1):61-65.

18. He P, Court MH, Greenblatt DJ, Von Moltke LL: Genotype-phenotype associations of cytochrome $\mathrm{P} 4503 \mathrm{~A} 4$ and $3 \mathrm{~A} 5$ polymorphism with midazolam clearance in vivo. Clin Pharmacol Ther 2005, 77(5):373-387.

19. Tucker AN, Tkaczuk KA, Lewis LM, Tomic D, Lim CK, Flaws JA: Polymorphisms in cytochrome P4503A5 (CYP3A5) may be associated with race and tumor characteristics, but not metabolism and side effects of tamoxifen in breast cancer patients. Cancer Lett 2005, 217(1):61-72.

20. Thompson EE, Kuttab-Boulos H, Witonsky D, Yang L, Roe BA, Di Rienzo A: CYP3A variation and the evolution of salt-sensitivity variants. Am J Hum Genet 2004, 75(6):1059-1069.

21. Young JH, Chang YP, Kim JD, Chretien JP, Klag MJ, Levine MA, Ruff CB, Wang NY, Chakravarti A: Differential susceptibility to hypertension is due to selection during the out-of-Africa expansion. PLoS Genet 2005, 1(6):e82.

22. Wrighton SA, Brian WR, Sari MA, Iwasaki M, Guengerich FP, Raucy JL, Molowa DT, Vandenbranden M: Studies on the expression and metabolic capabilities of human liver cytochrome P450IIIA5 (HLp3). Mol Pharmacol 1990, 38(2):207-213.

23. Bochud M, Bovet P, Burnier M, Eap CB: CYP3A5 and ABCB1 genes and hypertension. Pharmacogenomics 2009, 10(3):477-487.

24. Givens RC, Lin YS, Dowling AL, Thummel KE, Lamba JK, Schuetz EG, Stewart PW, Watkins PB: CYP3A5 genotype predicts renal CYP3A activity and blood pressure in healthy adults. J Appl Physiol 2003, 95(3):1297-1300.

25. Chen X, Wang H, Zhou G, Zhang X, Dong X, Zhi L, Jin L, He F: Molecular population genetics of human CYP3A locus: signatures of positive selection and implications for evolutionary environmental medicine. Environ Health Perspect 2009, 117(10):1541-1548.

26. Li J, Zhang L, Zhou H, Stoneking M, Tang K: Global patterns of genetic diversity and signals of natural selection for human ADME genes. Hum Mol Genet 2011, 20(3):528-540.

27. DeGiorgio M, Jakobsson M, Rosenberg NA: Out of Africa: modern human origins special feature: explaining worldwide patterns of human genetic variation using a coalescent-based serial founder model of migration outward from Africa. Proc Natl Acad Sci USA 2009, 106(38):16057-16062.

28. Li JZ, Absher DM, Tang H, Southwick AM, Casto AM, Ramachandran S, Cann HM, Barsh GS, Feldman M, Cavalli-Sforza LL, Myers RM: Worldwide human relationships inferred from genome-wide patterns of variation. Science 2008, 319(5866):1100-1104.

29. Prugnolle F, Manica A, Balloux F: Geography predicts neutral genetic diversity of human populations. Curr Biol 2005, 15(5):R159-R160.

30. Ramachandran S, Deshpande O, Roseman CC, Rosenberg NA, Feldman MW, Cavalli-Sforza $L L$ : Support from the relationship of genetic and geographic distance in human populations for a serial founder effect originating in Africa. Proc Natl Acad Sci USA 2005, 102(44):15942-15947.

31. Browning SL, Tarekegn A, Bekele E, Bradman N, Thomas MG: CYP1A2 is more variable than previously thought: a genomic biography of the gene behind the human drug-metabolizing enzyme. Pharmacogenet Genomics 2010, 20(11):647-664

32. Horsfall L, Zeitlyn D, Tarekegn A, Bekele E, Thomas MG, Bradman N, Swallow DM: Prevalence of clinically relevant UGT1A alleles and haplotypes in African populations. Ann Hum Genet 2011, 75(2):236-246.

33. Veeramah KR, Thomas MG, Weale ME, Zeitlyn D, Tarekegn A, Bekele E, Mendell NR, Shephard EA, Bradman N, Phillips IR: The potentially deleterious functional variant flavin-containing monooxygenase $2^{*} 1$ is at high frequency throughout sub-Saharan Africa. Pharmacogenet Genomics 2008, 18(10):877-886.

34. Croitoru A-E, Piticar A, Imbroane AM, Burada DC: Spatiotemporal distribution of aridity indices based on temperature and precipitation in the extra-Carpathian regions of Romania. Theor Appl Climatol 2012

35. Nei M, Kumar S: Molecular evolution and phylogenetics. New York: Oxford University Press; 2000.

36. Kitano T, Liu YH, Ueda S, Saitou N: Human-specific amino acid changes found in 103 protein-coding genes. Mol Biol Evol 2004, 21(5):936-944.

37. Burk O, Koch I, Raucy J, Hustert E, Eichelbaum M, Brockmoller J, Zanger UM, Wojnowski L: The induction of cytochrome P450 3A5 (CYP3A5) in the human liver and intestine is mediated by the xenobiotic sensors pregnane $\mathrm{X}$ receptor (PXR) and constitutively activated receptor (CAR). J Biol Chem 2004, 279(37):38379-38385.

38. Lin YS, Dowling AL, Quigley SD, Farin FM, Zhang J, Lamba J, Schuetz EG, Thummel KE: Co-regulation of CYP3A4 and CYP3A5 and contribution to hepatic and intestinal midazolam metabolism. Mol Pharmacol 2002, 62(1):162-172.

39. Busi F, Cresteil T: CYP3A5 mRNA degradation by nonsense-mediated mRNA decay. Mol Pharmacol 2005, 68(3):808-815.

40. Kimura M: The neutral theory of molecular evolution. Sci Am 1979, 241(5):98-100. 102, 108 passim.

41. Fay JC, $\mathrm{Wu} \mathrm{Cl}$ : Hitchhiking under positive darwinian selection. Genetics 2000, 155(3):1405-1413.

42. Plaster CA: Variation in Y chromosome, mitochondrial DNA, and labels of identity in Ethiopia. University College London, Research Department of Genetics, Evolution and Environment: PhD thesis; 2011.

43. Pagani L, Kivisild T, Tarekegn A, Ekong R, Plaster C, Gallego Romero I, Ayub Q, Mehdi SQ, Thomas MG, Luiselli D, Bekele E, Bradman N, Balding DJ, Tyler-Smith C: Ethiopian genetic diversity reveals linguistic stratification and complex influences on the Ethiopian gene pool. Am J Hum Genet 2012, 91(1):83-96.

44. Slatkin M, Rannala B: Estimating allele age. Annu Rev Genomics Hum Genet 2000, 1:225-249.

45. Rannala B, Bertorelle $\mathrm{G}$ : Using linked markers to infer the age of a mutation. Hum Mutat 2001, 18(2):87-100.

46. Tremblay $\mathrm{M}$, Vezina $\mathrm{H}$ : New estimates of intergenerational time intervals for the calculation of age and origins of mutations. Am J Hum Genet 2000, 66(2):651-658.

47. Griffiths RC, Marjoram P: Ancestral inference from samples of DNA sequences with recombination. J Comput Biol 1996, 3(4):479-502.

48. Cruciani F, Santolamazza P, Shen P, Macaulay V, Moral P, Olckers A, Modiano D, Holmes S, Destro-Bisol G, Coia V, Wallace DC, Oefner PJ, Torroni A, Cavalli-Sforza LL, Scozzari R, Underhill PA: A back migration from Asia to sub-Saharan Africa is supported by high-resolution analysis of human Y-chromosome haplotypes. Am J Hum Genet 2002, 70(5):1197-1214.

49. Salas A, Richards M, De la Fe T, Lareu MV, Sobrino B, Sanchez-Diz P, Macaulay V, Carracedo A: The making of the African mtDNA landscape. Am J Hum Genet 2002, 71(5):1082-1111.

50. Lovell A, Moreau C, Yotova V, Xiao F, Bourgeois S, Gehl D, Bertranpetit J, Schurr E, Labuda D: Ethiopia: between Sub-Saharan Africa and western Eurasia. Ann Hum Genet 2005, 69(Pt 3):275-287.

51. Gebeyehu E, Engidawork E, Bijnsdorp A, Aminy A, Diczfalusy U, Aklillu E: Sex and CYP3A5 genotype influence total CYP3A activity: high CYP3A activity and a unique distribution of CYP3A5 variant alleles in Ethiopians. Pharmacogenomics J 2011, 11(2):130-137.

52. Kivisild T, Reidla M, Metspalu E, Rosa A, Brehm A, Pennarun E, Parik J, Geberhiwot T, Usanga E, Villems R: Ethiopian mitochondrial DNA heritage: tracking gene flow across and around the gate of tears. Am J Hum Genet 2004, 75(5):752-770.

53. Mukonzo JK, Waako P, Ogwal-Okeng J, Gustafsson LL, Aklillu E: Genetic variations in $A B C B 1$ and $C Y P 3 A 5$ as well as sex influence quinine disposition among Ugandans. Ther Drug Monit 2010, 32(3):346-352.

54. Josephson F, Allqvist A, Janabi M, Sayi J, Aklillu E, Jande M, Mahindi M, Burhenne J, Bottiger Y, Gustafsson LL, Haefeli WE, Bertilsson L: CYP3A5 genotype has an impact on the metabolism of the HIV protease inhibitor saquinavir. Clin Pharmacol Ther 2007, 81(5):708-712.

55. Oliveira E, Pereira R, Amorim A, McLeod H, Prata MJ: Patterns of pharmacogenetic diversity in African populations: role of ancient and recent history. Pharmacogenomics 2009, 10(9):1413-1422. 
56. Sgaier SK, Jha P, Mony P, Kurpad A, Lakshmi V, Kumar R, Ganguly NK: Public health. Biobanks in developing countries: needs and feasibility. Science 2007, 318(5853):1074-1075.

57. Lamba JK, Lin YS, Schuetz EG, Thummel KE: Genetic contribution to variable human CYP3A-mediated metabolism. Adv Drug Deliv Rev 2002, 54(10):1271-1294

58. Butler D: Genomics. Are you ready for the revolution? Nature 2001, 409(6822):758-760.

59. Chung RT: Reaping the early harvest of the genomics revolution. Gastroenterology 2010, 138(5):1653-1654.

60. Defrancesco L: Life Technologies promises $\$ 1,000$ genome. Nat Biotechnol 2012, 30(2):126.

61. Beleza S, Gusmao L, Amorim A, Carracedo A, Salas A: The genetic legacy of western Bantu migrations. Hum Genet 2005, 117(4):366-375.

62. Voight BF, Kudaravalli S, Wen X, Pritchard JK: A map of recent positive selection in the human genome. PLoS Biol 2006, 4(3):e72.

63. Conrad DF, Jakobsson M, Coop G, Wen X, Wall JD, Rosenberg NA, Pritchard JK: A worldwide survey of haplotype variation and linkage disequilibrium in the human genome. Nat Genet 2006, 38(11):1251-1260.

64. Sabeti PC, Schaffner SF, Fry B, Lohmueller J, Varilly P, Shamovsky O, Palma A, Mikkelsen TS, Altshuler D, Lander ES: Positive natural selection in the human lineage. Science 2006, 312(5780):1614-1620.

65. Gerbault P, Liebert A, Itan Y, Powell A, Currat M, Burger J, Swallow DM Thomas MG: Evolution of lactase persistence: an example of human niche construction. Philos Trans R Soc Lond B Bio/ Sci 2011, 366(1566):863-877.

66. Tishkoff SA, Reed FA, Ranciaro A, Voight BF, Babbitt CC, Silverman JS, Powell K, Mortensen HM, Hirbo JB, Osman M, Ibrahim M, Omar SA, Lema G, Nyambo TB, Ghori J, Bumpstead S, Pritchard JK, Wray GA, Deloukas P: Convergent adaptation of human lactase persistence in Africa and Europe. Nat Genet 2007, 39(1):31-40.

67. Thompson EE, Kuttab-Boulos H, Yang L, Roe BA, Di Rienzo A: Sequence diversity and haplotype structure at the human CYP3A cluster. Pharmacogenomics J 2006, 6(2):105-114.

68. Whittaker JC, Harbord RM, Boxall N, Mackay I, Dawson G, Sibly RM: Likelihood-based estimation of microsatellite mutation rates. Genetics 2003, 164(2):781-787.

69. Biswas S, Akey JM: Genomic insights into positive selection. Trends in genetics: TIG 2006, 22(8):437-446.

70. Samani NJ, Tomaszewski M, Schunkert $H$ : The personal genome-the future of personalised medicine? Lancet 2010, 375(9725):1497-1498

71. Pakenham T: The scramble for Africa, 1876-1912. London: Weidenfeld and Nicolson; 1991.

72. Thomas MG, Bradman N, Flinn HM: High throughput analysis of 10 microsatellite and 11 diallelic polymorphisms on the human $\mathrm{Y}$ chromosome. Hum Genet 1999, 105(6):577-581.

73. Excoffier L, Laval G, Schneider S: Arlequin (version 3.0): an integrated software package for population genetics data analysis. Evol Bioinform Online 2005, 1:47-50

74. Stephens M, Smith NJ, Donnelly P: A new statistical method for haplotype reconstruction from population data. Am J Hum Genet 2001, 68(4):978-989.

75. Librado P, Rozas J: DnaSP v5: a software for comprehensive analysis of DNA polymorphism data. Bioinformatics 2009, 25(11):1451-1452.

76. Smith RS, Gregory J: The last glacial cycle: transient simulations with an AOGCM. Clim Dyn 2012, 38:1545-1560.

77. Paradis E, Claude J, Strimmer K: APE: analyses of phylogenetics and evolution in R language. Bioinformatics 2004, 20(2):289-290.

78. Urban SCGDL: The ecodist package for dissimilarity-based analysis of ecological data. J Stat Software 2007, 22(7):19.

79. Cartharius K, Frech K, Grote K, Klocke B, Haltmeier M, Klingenhoff A, Frisch M, Bayerlein M, Werner T: MatInspector and beyond: promoter analysis based on transcription factor binding sites. Bioinformatics 2005, 21(13): 2933-2942.

80. Adzhubei IA, Schmidt S, Peshkin L, Ramensky VE, Gerasimova A, Bork P, Kondrashov AS, Sunyaev SR: A method and server for predicting damaging missense mutations. Nat Methods 2010, 7(4):248-249.

81. Reese MG, Eeckman FH, Kulp D, Haussler D: Improved splice site detection in genie. J Comput Biol 1997, 4(3):311-323.

82. Goldstein DB, Ruiz Linares A, Cavalli-Sforza LL, Feldman MW: Genetic absolute dating based on microsatellites and the origin of modern humans. Proc Natl Acad Sci USA 1995, 92(15):6723-6727.
83. Slatkin M: A measure of population subdivision based on microsatellite allele frequencies. Genetics 1995, 139(1):457-462.

84. Farrall M, Weeks DE: Mutational mechanisms for generating microsatellite allele-frequency distributions: an analysis of 4,558 markers. Am J Hum Genet 1998, 62(5):1260-1262.

85. Behar DM, Thomas MG, Skorecki K, Hammer MF, Bulygina E, Rosengarten D, Jones AL, Held K, Moses V, Goldstein D, Bradman N, Weale ME: Multiple origins of ashkenazi levites: $Y$ chromosome evidence for both near eastern and european ancestries. Am J Hum Genet 2003, 73(4):768-779.

\section{doi:10.1186/1471-2156-14-34}

Cite this article as: Bains et al:: Molecular diversity and population structure at the Cytochrome P450 3A5 gene in Africa. BMC Genetics 2013 $14: 34$.

\section{Submit your next manuscript to BioMed Central and take full advantage of:}

- Convenient online submission

- Thorough peer review

- No space constraints or color figure charges

- Immediate publication on acceptance

- Inclusion in PubMed, CAS, Scopus and Google Scholar

- Research which is freely available for redistribution

Submit your manuscript at www.biomedcentral.com/submit
C Biomed Central 